\title{
MOTHERS' EXPERIENCES OF A CHILD WITH LEARNING DISABILITIES: \\ A PHENOMENOLOGICAL STUDY
}

CENTRE FOR NEWFOUNDLAND STUDIES

TOTAL OF 10 PAGES ONLY MAY BE XEROXED

(Without Author's Permission)

JUDITH G. MOODY 


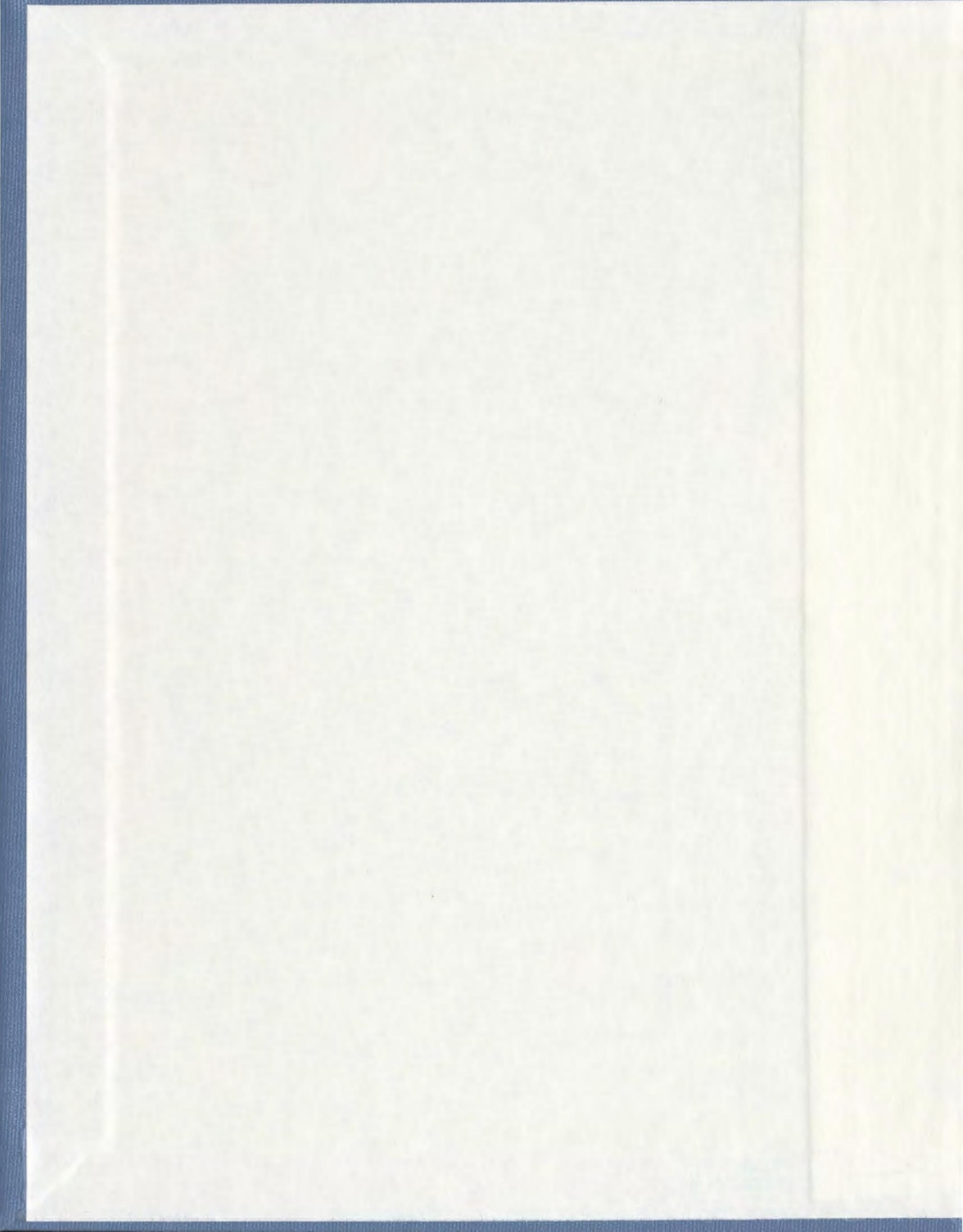






\author{
National Library \\ of Canada \\ Acquisitions and \\ Bibliographic Services \\ 395 Wellington Street \\ Ottawa ON K1A ON4 \\ Canada
}

Bibliothèque nationale

du Canada

Acquisisitons et services bibliographiques

395 , rue Wellington Ottawa ON K1A ON4

Canada
Your file Votre référence ISBN: 0-612-93043-2

Our file Notre référence ISBN: 0-612-93043-2
The author has granted a nonexclusive licence allowing the National Library of Canada to reproduce, loan, distribute or sell copies of this thesis in microform, paper or electronic formats.

The author retains ownership of the copyright in this thesis. Neither the thesis nor substantial extracts from it may be printed or otherwise reproduced without the author's permission.
L'auteur a accordé une licence non exclusive permettant à la Bibliothèque nationale du Canada de reproduire, prêter, distribuer ou vendre des copies de cette thèse sous la forme de microfiche/film, de reproduction sur papier ou sur format électronique.

L'auteur conserve la propriété du droit d'auteur qui protège cette thèse. $\mathrm{Ni}$ la thèse ni des extraits substantiels de celle-ci ne doivent être imprimés ou aturement reproduits sans son autorisation.
In compliance with the Canadian

Privacy Act some supporting forms may have been removed from this dissertation.

While these forms may be included in the document page count, their removal does not represent any loss of content from the dissertation.
Conformément à la loi canadienne sur la protection de la vie privée, quelques formulaires secondaires ont été enlevés de ce manuscrit.

Bien que ces formulaires aient inclus dans la pagination, il n'y aura aucun contenu manquant. 



\title{
MOTHERS' EXPERIENCES OF A CHILD WITH LEARNING DISABILITIES: A PHENOMENOLOGICAL STUDY
}

\author{
by \\ Judith G. Moody, B.N. \\ A thesis submitted to the \\ School of Graduate Studies \\ in partial fulfilment of the \\ requirements for the degree of \\ Master of Nursing \\ School of Nursing \\ Memorial University of Newfoundland
}

August 2003

St. John's

Newfoundland and Labrador 


\section{Dedicated to}

all mothers who listen to their hearts and continually support their children with a learning disability. 


\section{ABSTRACT \\ Mothers' Experiences of a Child with Learning Disabilities: \\ A Phenomenological Study}

Learning disabilities have a significant impact not only on the affected individual but also on other family members. The mother often is the most affected family member as she tries to understand her child's difficulties while trying to discover the nature of the problem. Learning disabilities are usually not identified until school entry or even later depending on the nature of the disability. The goal of this phenomenological study is to understand what it is like to be a mother of a child with a learning disability. Ten mothers participated in the study and were asked to describe their experiences to gain insight into this mothering experience. Unstructured individual interviews were conducted. Thematic analysis was conducted using van Manen's approach. Six themes were identified from the data analysis: searching for answers, easing the child's struggle, need for assistance and understanding, no time for self, isolating and lonely life, and an uncertain future. Mothers indicated the experience was emotional, challenging, and stressful. This research adds to the body of knowledge on mothering in the area of learning disabilities. 


\section{ACKNOWLEDGEMENTS}

A heartfelt thank-you is extended to all the participants who took the time to allow me to experience from them a sharing of their feelings and thoughts about what it is like to be a mother of a child with a learning disability.

Many thanks and gratitude go to the Learning Disabilities Association of Newfoundland and Labrador for their interest in this study.

Sincere appreciation goes to my co-supervisors, Dr. Shirley Solberg and Ms. Doreen Dawe for their guidance, support, and accessibility during this study.

Sincere thanks to my professors in the graduate program who provided me with an enriching learning experience.

I would also like to acknowledge Lindsay Glynn of the Health Sciences Library, who was always willing to listen, provided assistance in the numerous discussions surrounding my search for literature, and my area of research interest.

I want to especially thank by husband, Doug, and my two children, Sara and Andrew, who continually supported me, always provided encouragement and understanding, and who helped make my desire to start and complete this program of study a reality. Without their assistance and love I would not have been able to achieve this goal. 


\section{TABLE OF CONTENTS}

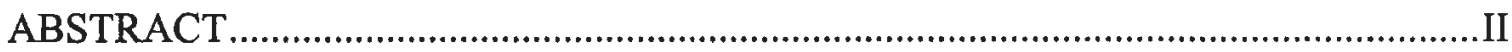

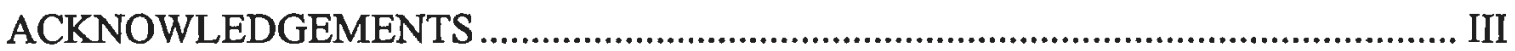

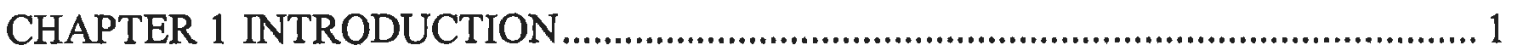

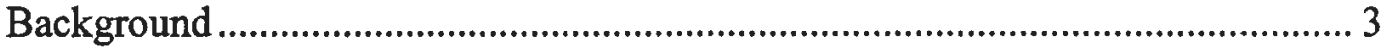

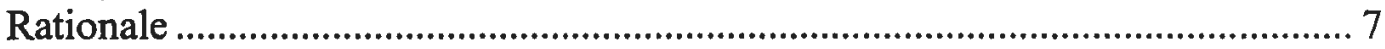

Purpose

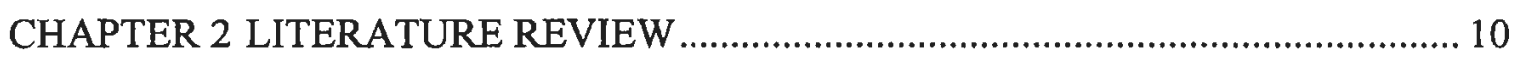

The Complexity of Learning Disabilities ............................................................... 11

Learning Disabilities and Families ...................................................................... 14

Learning Disabilities and Siblings....................................................................... 21

Effects of Learning Disabilities on the Affected Individual................................. 23

Summary of Reviewed Literature........................................................................... 25

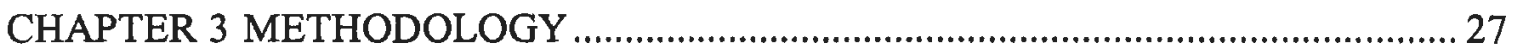

Phenomenology as Methodology ...................................................................... 27

Research Methods .............................................................................................. 30

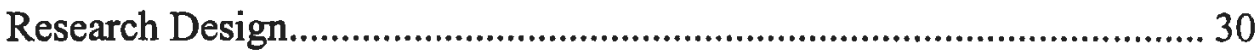

Participants............................................................................................ 30

Criteria for Participant Selection ............................................................ 31

Data Collection ...................................................................................... 32

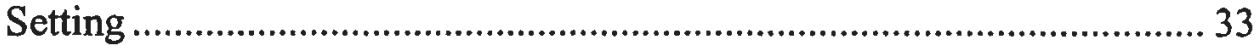

Data Analysis .......................................................................................... 33

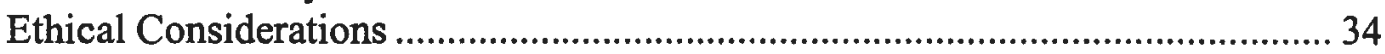

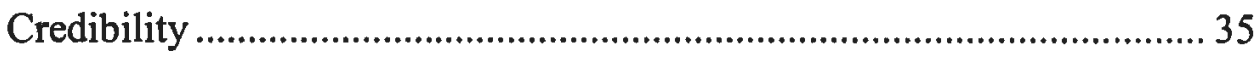

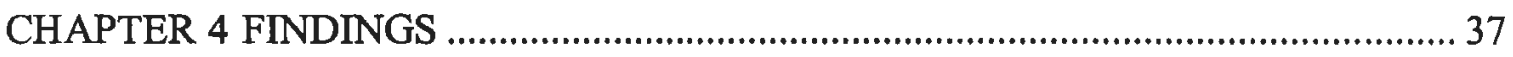

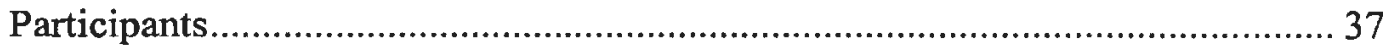

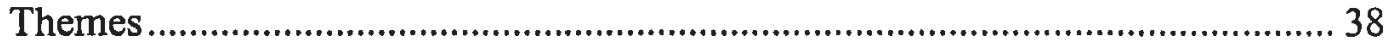

Searching for Answers............................................................................ 38

Easing the Child's Struggle ....................................................................... 43

Need for Assistance and Understanding .................................................... 48

No Time for Self .................................................................................. 55 


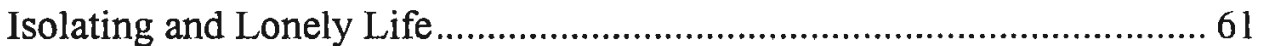

An Uncertain Future .................................................................. 65

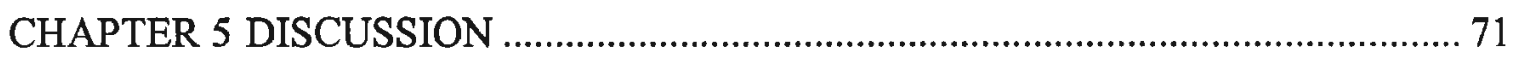

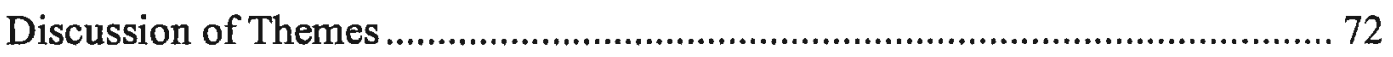

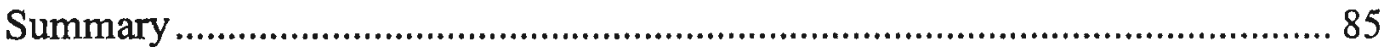

CHAPTER 6 NURSING IMPLICATIONS AND CONCLUSION.................................. 86

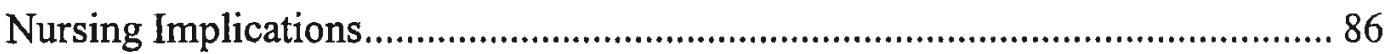

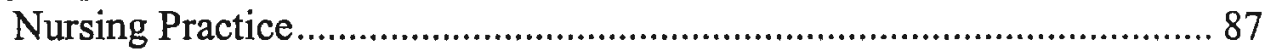

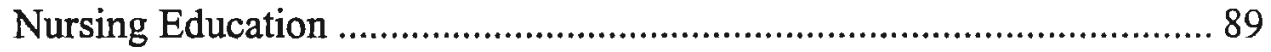

Nursing Research ............................................................................. 90

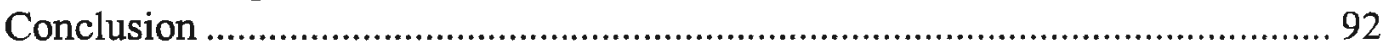

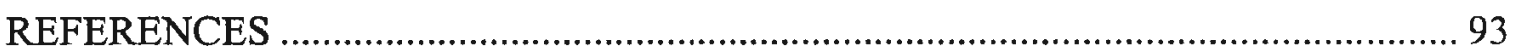

APPENDIX A LETTER TO LEARNING DISABILITIES ASSOCIATION ...............99

APPENDIX B LETTER OF CONSENT TO PARTICIPATE IN NURSING

RESEARCH ........................................................................ 101

APPENDIX C LETTER OF APPROVAL FROM HUMAN INVESTIGATION COMMITTEE 


\section{CHAPTER 1}

\section{INTRODUCTION}

The nature of this study is to understand mothers' experiences with children who have learning disabilities. Research in recent years has led to an ever increasing knowledge and awareness of the extent and impact of learning disabilities. The Learning Disabilities Association of Canada (LDAC, 2002) estimates that 10\% of Canadians have a learning disability. While a large portion of the population is, thus, directly affected by learning disabilities, a much larger portion comprised of parents and siblings is indirectly affected by this condition. The ways in which learning disabilities are manifested in individuals are well documented, however, very little is known about mothers' experiences. This study focuses on mothers of children with learning disabilities. Insight is provided into their unique experiences and adds to the body of knowledge regarding parenting and learning disabilities.

Mothers perform a multiplicity of roles in their daily lives. They manage households, childcare, co-ordination of activities, schoolwork, meal planning, and for many, employment outside the home. They also look after the health of family members and in particular for younger children. The challenges associated with these many roles are confounded when a child has a learning disability (Margalit \& Heiman, 1986). Since mothers tend to be more closely involved with their children when they are younger, than fathers are, they are more likely to become aware of problems in areas of growth and development. Mothers become mindful of concerns through observation of other same- 
age children, comparison of siblings at the same age, and/or interaction with other mothers in a variety of settings. They are often the ones who approach professionals consistently for exploration and confirmation of their initial concerns based on insight and intuition (Faerstein, 1986).

Mothers themselves struggle with not knowing what is wrong with their child when they suspect a problem. Mothers also tend to take responsibility in communicating concerns they have with fathers and the rest of the family. The initial symptoms of a learning disability are behavioural, often including impulsivity, irritability, and limited attention span (Faerstein, 1981). Children exhibiting these symptoms which vary in severity, have a negative effect on existing family routines and household functioning. This situation may go on for years until the specific problem is identified. Living with children whose behaviours are unpredictable is frustrating for all concerned (Comfort, 1992).

When a learning disability is confirmed mothers may need to change established patterns to accommodate any suggested changes for dealing with the problem within the household. New roles may have to be assumed and/or existing roles expanded, such as mediating, preplanning, advocating, intervening, and adapting. While all of these things are happening, mothers provide emotional support to the child with a learning disability, and attempt to balance the time and attention required for other family members. Mothers most often listen to their child when he/she is hurt, intervene if social problems arise, and act as referees among other family members. They are most often the ones involved in the day to day issues with the child. 
Mothers are usually the ones who transport the child to appointments and consult with professionals. If mothers are employed outside the home time to attend appointments has to be arranged. After an initial visit to a professional further assessments by other disciplines may be required in an attempt to discover the nature of the problem. This requires time away from other responsibilities. If waiting time for assessment is lengthy, how do mothers cope with their individual situations?

\section{Background}

Learning disabilities are considered "life disabilities" and "lifelong" disabilities (Silver, 1996). Learning disabilities that hinder reading, writing, and mathematics also affect activities like playing baseball, setting a table for meals, getting dressed, and keeping schoolwork and a bedroom organized (Silver). A child with a learning disability grows up to be an adult with a learning disability. With the right skills and strategies for learning these children can achieve as well as others. These children need to build on their strengths and achieve success rather than focus on their weaknesses and produce failure (Silver).

Mothers work at identifying strengths to promote success for their children. Simple decisions, such as choosing activities, schools, and camps become very complex, challenging, and stressful for mothers of children with a learning disability. To promote success in these areas, considerable exploration and research is required to investigate options so appropriate choices can be made. These decisions usually involve considerable investment of time and energy. Due to the complexity of a child's situation, mothers of 
children with learning disabilities are unsure of the outcome of many of their decisions. This uncertainity becomes a part of their everyday life.

These mothers become concerned when they do not know how to effectively deal with the behaviours displayed and the underlying problems of their children. They try to find answers to their children's problem. Mothers suspecting there is a problem are angry when told by professionals that the problem will go away, or there is no problem. Mothers are then left to deal with the situation themselves increasing feelings of frustration. They begin to feel isolated due to lack of support.

Confirmation on the other hand is a relief for some. Others may feel anger, disbelief, and shock when their child's learning disability is confirmed (Smith, 1998). Sometimes parents blame each other, or themselves, or review past events looking for a cause. Some parents may react by not getting involved in their child's education, yet others may demand too much and push their child to perform beyond their capabilities (Smith). Some parents may debate and/or not comprehend the severity of the problem, resulting in children not getting the support they need.

Mothers need to accept and adjust to the reality that they have a child with a learning disability. This process could involve mourning the loss of what was expected (Smith, 1998). Disappointment over this loss may lead to over-protectiveness. While over-protectiveness may be a natural response, this over-involvement sometimes results in decreasing children's learning experiences with respect to dealing with conflicts, problem solving, guidance, and limits that children require (Smith). Whatever the response mothers are affected. 
Many mothers of children with disabilities elect to keep their pain and exhaustion concealed (Greenspan, 1998). The pressures of mothering become more intense and isolating when faced with a child's disability. These women search numerous sources as they try and discover information that might suggest a diagnosis. They often have to work with various systems, for example, health and education, as well as a number of professionals. Emotions like sorrow, fear, and frustration come with being a mother of a child with special needs (Greenspan).

Siblings are also affected by having a brother or sister with a learning disability and this requires additional care on the part of the mother. Adjustment of siblings depends to a great extent on how mothers / parents adjust and respond to the diagnosis themselves. Siblings require understandable explanations, as well as, descriptions of strengths and weaknesses of their brother or sister to prevent any guilt and confusion (Smith, 1998). This is a huge responsibility for mothers, while trying to seek answers and solutions to the problems themselves.

Siblings without learning disabilities sometimes become jealous of the time that the increased attention their sibling receives from their parents takes especially when rules are different (Smith, 1998). Siblings may also be embarrassed by the behaviour of their brother or sister. They are often expected to take on additional responsibilities that create stress and a feeling of decreased support from their parents. Sometimes pressure is put on siblings to excel in areas of academics and athletics. This may result in increased anxiety or poor peer relations causing decreased performance. Other siblings demonstrate a greater acceptance, tolerance, patience, and thus, a better self-concept (Smith). 
Mothers need to be aware of a sibling's feelings, listen to their concerns, and acknowledge their needs. They need to be conscious of the possibility of a reduced selfconcept because the unaffected child does not feel special. They also need to be cognizant of the new roles the sibling might have to take on and what effect this might have. One of the major challenges for mothers is to emphasize to the child without a learning disability that individuals have different needs and some children require more of a mother's time than others. To provide reassurance and balance the needs of other family members is a daunting task for mothers.

Mothers also need to be aware that a child with a learning disability may be affected by being compared with a higher achieving sibling, particularly if the sibling is younger. Mothers need to nurture the sibling relationship, since siblings without learning disabilities may serve as good role models (Smith, 1998). Overall family life is directed by the needs of a child with a learning disability. Mothers often take the lead to ensure that emotional, educational, and medical needs are being met. Activities such as vacation decisions, recreation time, and management of resources need consideration. Additional financial sources may have to be secured, or cutbacks made in other areas in order to meet the need for private assessments, tutorial services, private schools, and professional services.

It is reasonable to assume, therefore, that having a child with a learning disability affects a much greater portion of the population than the $10 \%$ of the population identified with the condition. Mothers of these children are greatly affected. 


\section{Rationale}

Mothers play an instrumental role in the life of a family. They are the primary care givers for all members in a household. Mothers are knowledgeable and contribute significantly to the educational and social development of their children (Bender, 2001). While motherhood is very fulfilling and an important role for women, mothering a child with a learning disability and the emotional effect of this is not well understood. This is due to the invisibility of some of their stresses.

Mothers understand a child with special needs has limitations. There is evidence that disabilities can have serious long-term consequences for the development of children and their ability to assume normal roles and responsibilities as adults (Betz, 1998; Sawin et al., 1999). Some of these consequences may be directly attributable to specific learning disabilities. Limitations in skills such as reading, communications, and mathematics, for example, may limit job productivity and employment opportunities.

Decreased self-esteem, inability to develop and maintain relationships, lack of motivation, and reluctance to complete an education are some other outcomes that may stem from stresses associated with learning disabilities. These may in turn affect an individual's ability to function in the workplace, as well as, their health and social well being, requiring intervention by medical and/or social agencies. The possibility of any of these scenarios worries mothers. There is no easy way to predict how any children will function and where they will end up in the adult world. The picture becomes more complex, however, when a mother has a child with special needs. 
Most children with a learning disability have average or above average intelligence. When mothers see how their child demonstrates success in a subject area and not in others, they are compelled to do something about the situation. They know a fundamental underpinning of a satisfactory and productive life is the successful transition into post-secondary education and/or the work force with a focus rooted in appropriate, realistic career, and personal choices. Mothers are aware that in today's world a skilled workforce is essential for prosperity and success in the new economy where barriers to trade are slowly vanishing, capital can be moved faster, and natural resources seem to be less appreciated. The government of Canada indicates by 2004 more than $70 \%$ of all new jobs in Canada will demand some form of post-secondary education, $25 \%$ of new jobs will require a university degree, and only $6 \%$ of new jobs will be held by individuals who have not completed high school (Knowledge Matters, 2002). The goal for mothers of children with learning disabilities, therefore, is to make sure their child is identified as soon as possible and appropriate interventions are put in place in a timely way. These measures are necessary to ensure educational and employment opportunities, job success, citizenship, and active community involvement in the adult world for their child.

The impetus for this research comes from my many years of nursing practice and as a mother. Having worked as a community health nurse for many years, I saw many mothers and children, in well child clinic visits, pre-school health assessments, school settings, and while visiting a variety of individuals with acute and chronic illness in their homes. I became increasingly aware of the problem learning disabilities has on children and their families. Practice in child health involved listening to the concerns of mothers, 
answering their questions, conducting assessments, and referring children for further assessments to an appropriate professional. I have heard mothers express concerns such as "my child seems to learn differently", "is unlike his/her sibling", and "I am not able to put my finger on what the problem is, but something is different about this child". I often wondered what happened to these mothers, were their concerns satisfactorily addressed, what were the responses of other professionals, what were the results of assessments, and how did these mothers cope. Maternal health is always a concern when a mother has a child with special needs.

It was important to understand these mothers' experiences as they dealt with their children on a daily basis. For this reason I selected a phenomenological approach as that approach would help me gain a greater understanding.

\section{Purpose}

This research will add to the body of knowledge of mothering a child with learning disabilities. The purpose of this research is to better understand and provide insight into the meaning of that everyday lived experience as described by these mothers. The research question that will be addressed in this study is: What is it like to be a mother of a child with a learning disability? 


\section{CHAPTER 2}

\section{LITERATURE REVIEW}

This chapter presents research that contributes to an understanding of learning disabilities and parenting. There is a vast amount of literature that focuses on children and adolescents with academic difficulties, school-related behavioural, and social / emotional problems requiring referral to professionals. Many children have difficulty performing academically at age appropriate levels, therefore it is difficult to differentiate children with true learning disabilities from children with other problems. Learning disabilities, their specific deficits, and learning performances have been well addressed in the literature by researchers in psychology, education, and other disciplines. Despite the implications that learning disabilities have for the health of the affected individual and his/her family, little nursing research has been conducted in this area. In particular not much has been done on the experiences of mothers of children with learning disabilities. Most of the literature in nursing focuses on severely disabled children, children with acute and chronic illness, treatment of these illnesses, as well as management in the hospital and home environment. As a consequence, we do not have much information on nursing strategies that would help these women and their children.

This literature review presents what is known about mothers' experiences with a child having a learning disability, as well as, related research, and identifies areas where further study is needed. As there are very few studies involving only mothers, the literature review encompasses findings involving either one or both parents. The 
literature is presented using the following categories: the complexity of learning disabilities, learning disabilities and families, learning disabilities and siblings, and the effects of learning disabilities on the affected individual. The latter category is included because it gives a good understanding of what mothers may have to deal with in their mothering roles.

\section{The Complexity of Learning Disabilities}

There has been considerable debate in the past over the exact nature of learning disabilities, however, a consensus seems to be emerging. Kavale's and Forness's (2000) critical analysis of the definitions of learning disabilities found a fundamental problem was that existing definitions failed to provide an exact statement of what is a learning disability. The difficulty is due to vague descriptions and relationships without any clear conceptualization (Kavale \& Forness). These authors, however, indicated that several ideas encompassed in previous definitions have converged, suggesting that learning disabilities are a heterogeneous group of disorders, presumably resulting from some central nervous system dysfunction. These disorders are associated with underachievement that may be seen in the areas of spoken language, thinking processes, and academics.

The current definition employed by the Learning Disabilities Association of Canada (LDAC, 2002) states that learning disabilities refer to a number of disorders that alter processing, organizing, retaining, understanding, or using verbal and/or non-verbal information. Such a disorder affects an individual's ability to either interpret what they 
see and hear, or to connect information from different parts of the brain (LDAC).

Individuals with learning disabilities demonstrate average or above average intelligence, may display significant difficulty on some tasks but excel in others, and may experience disability in academic, as well as social settings.

Learning disabilities result from genetic and/or neurological factors or an injury that alters brain functioning related to learning (LDAC, 2002). Learning disabilities may interfere with one or more of the following four areas: "oral language (listening, speaking, understanding), reading (decoding, phonetic knowledge, word recognition, comprehension), written language (spelling, written expression), and mathematics (computation, problem solving)" (LDAC, p.1). Learning disabilities may also affect organization, social perception, and/or interaction (LDAC).

Learning disabilities are not due to socio-economic factors, cultural differences, hearing and/or vision problems, or lack of motivation, however, these elements may further complicate challenges encountered by people with learning disabilities (LDAC, 2002). Learning disabilities may also be associated with attentional, behavioral, and emotional disorders, sensory impairments, or other medical problems (LDAC).

Learning disabilities cannot be seen, may go undetected, and are chronic conditions that do not go away (Selekman, 2002). They are often ignored by the health care system. When an affected child is admitted to the hospital for some medical and/or surgical reason, that condition gets priority and a learning disability usually goes undiscovered. Professional health care literature contained very little information about learning disabilities before the 1980 's (Selekman). Learning disabilities were not 
discussed in pediatric nursing textbooks, nor was there anything that addressed the effects of these conditions on a child and his/her family (Selekman).

Learning disabilities were usually discussed in conjunction with attention deficit hyperactivity disorder (ADHD) and dyslexia during the 1980's and 1990's. Many children had been diagnosed with ADHD in the twentieth century, therefore, nursing and nursing education gave more emphasis to this, and little consideration was paid to the diagnosis of learning disabilities (Selekman, 2002).

Concurrent disorders such as ADHD, and medical conditions, like hearing problems, add to the difficulties of individuals with learning disabilities. Children with learning disabilities and other disorders experience complex situations. Their circumstances often require interaction with several disciplines that may challenge the priority of interventions and require collaboration. Learning disabilities have the potential to negatively affect self-esteem, confidence, sense of achievement, as well as, an individual's capability to participate fully in many aspects of living especially socialization. These issues may in turn lead to mental health problems. If a child has a disability that interferes with listening, speaking, or understanding, there are implications for other aspects of their learning such as socialization. Mothers of children with learning disabilities, therefore, may require help from a variety of professionals. Since learning disabilities are a long-term problem affecting everyday living from childhood extending into adulthood, they must be regarded as a chronic condition (Silver, 1989). 


\section{Learning Disabilities and Families}

One literature review on families and learning disabilities (Faerstein, 1981) and one metasynthesis on mothering children with a variety of physical and mental difficulties (Nelson, 2002) was located. Faerstein's early review of the literature looked at stress and coping reactions in families with a child having a learning disability. Children with physical and mental handicaps were also included in the review. In terms of family reaction to learning disabilities, the author indicated that even before a diagnosis was confirmed, a family could be reacting unfavourably towards a child if behavioral problems were present. Early identification was, therefore, critical. If parents' emphasized academic success of their children, the discovery of a disability concerned them even more. The author reported that in order to help a child and family adapt, it was important to reassure parents and fully explain the child's problem. These measures helped reduce any guilt the parents experienced. Communication is essential between parents and professionals.

The strength of Faerstein's (1981) review was the conclusion that in order to help families of a child with a learning disability, it was important to understand how they experienced the problem at home, in the community, and in the medical setting. While an overview of the studies and their findings was presented, specific methodologies, and sample sizes were not identified in the review.

The inclusion of the metasynthesis by Nelson (2002) was relevant for several reasons. One study specifically focused on attention deficit hyperactivity disorder, a condition commonly associated with a learning disability. Mothers were exclusively 
represented. This study provided insight into the mothering experience and the roles / responsibilities / feelings that surround having a child with special needs. While the focus was on specific disabilities / diseases, for example, cerebral palsy, adult schizophrenia and attention deficit disorder, various themes emerged that were similar for all mothers. This most recent work emphasizes the need to pay more attention to learning disabilities in nursing.

In this metasynthesis of mostly qualitative studies, Nelson (2002) examined the development of knowledge on mothering "other-than-normal" children (those with mental and/or physical challenges) using Noblit's and Hare's (1988) meta-ethnographic comparative method of synthesizing qualitative studies. Thirteen themes were identified in the twelve studies selected. The author suggested a four step process in mothering these children and that consisted of: (a) becoming a mother of a child with a disability, (b) negotiating a new kind of mothering, (c) dealing with life, and (d) the process of acceptance and denial. Themes identified were classified under the various steps. The heterogeneity of the groups of mothers sampled, as well as, the broad range in ages and disabilities, were both strengths and limitations (Nelson). The use of different methodologies, as identified by the author, was a limitation making comparison of results complex.

One of the strengths of the metasynthesis by Nelson (2002) was that mothers were chosen as the sample for exploration. Implications for nursing practice, specifically, the need to listen to what mothers say about their children, to identify their requirements, and to co-ordinate care that benefits all family members, were other strengths. Suggestions 
for further research included completing a metasynthesis of the mothering experience with distinct groups of children, or sets of studies, using the same methodology. The author also recommended that other health care professionals think about maternal burden, what kind of disability exists, what are the special needs of a child, and the length of time a family has been dealing with its situation. Health care professionals need to support mothers / families and try to understand their unique experiences. The author suggested the need for nurses to effectively work with mothers providing hope through the use of short-term goals so mothers feel they are making some progress in their challenging situations.

The review by Faerstein (1981) revealed that very little is known about the experiences of mothers having children with learning disabilities. This continues to be the case. A gap exists in the knowledge about how families - especially mothers - react, adapt, respond, and remain healthy when faced with a child who has a learning disability.

More recently Waggoner and Wilgosh (1990) examined the experiences and concerns of parents of children with learning disabilities by conducting in-depth interviews. Seven themes were identified from the data. These were: (a) need for parental involvement in their child's education, (b) supportive and non-supportive parental relationships with school, (c) need for support for parents from a variety of sources, such as, family, friends, parent, and/or professional groups, (d) social concerns of their child, (e) concerns about child's future and career, (f) emotional strains of parenting related to assessment, lack of self-esteem, and feelings of emotional pain experienced by parents, and $(\mathrm{g})$ effects on the family due to extra time consuming demands. Some parents in this 
study reported siblings learned to accept and tolerate the learning disability of their brother / sister, as well as, the need for their parents to spend more time with that child. Some siblings were reported by their parents to have learned valuable lessons about struggles that others face in life.

Other studies suggested that parents of children with learning disabilities experienced more stress than parents who did not have a child with a learning disability (Dyson, 1996; Fuller \& Rankin, 1994). Mothers of children grouped as emotionally impaired and those grouped with learning disabilities experienced more stress than parents of children in regular education classes (Fuller \& Rankin). Family functioning was not affected by having a child with a learning disability even though family routines were altered and sibling interactions disrupted (Dyson). Family members had positive relationships among each other, used rules to operate, and used recreational / cultural activities to promote greater personal growth (Dyson; Margalit \& Heiman, 1986). Dyson found that families gave a lot of time and energy to their child with a learning disability, although some parents were reported to have had difficulty accepting the diagnosis because of their own personal level of achievement.

Reactions by mothers to the diagnosis of a learning disability varied. Some mothers were relieved to know what the problem was (Faerstein, 1986). Faerstein indicated these mothers were able to separate out the idea of something being wrong with their child from their own personal feelings in order to get help for their child. Mothers were found to experience isolation before a diagnosis of a child's learning disability, however, this lessened when the problem was identified. Faerstein indicated that mothers 
felt that society did not accept them or their child because they were not able to show others that their child was actually ill. Mothers reported feeling isolated within the community and often had little support from families, husbands, and parents. The reactions of these parents were contrary to Dyson (1996) who found that parents had trouble accepting a child's disability. Both of the above studies found the time involved in seeking and reaching a diagnosis was long.

Self-concept of children with learning disabilities was lower compared to their siblings, however children with learning disabilities functioned well and positively affected the self-concept of their brother or sister (Dyson, 1996). Other research by Grolnick and Ryan (1990) and Rogers and Saklofske (1985) found that children with a learning disability had a low self-concept. Parental experiences of their child with a learning disability were reported to be more negative due to the child's skill and behavioral deficits (Margalit \& Heiman, 1986) and unsatisfactory school experiences (Dyson; Waggoner \& Wilgosh, 1990). Delay in identification of a child's learning disability and program placement was also reported to be a frustration for parents.

In a study comparing parents of boys with and without learning disabilities Margalit and Heiman (1986) found higher levels of self-anxiety, more controlled and ordered family climate, as well as emphasis placed on personal achievement in parents of boys with learning disabilities. Age appropriate (typical) behaviour by a child with a learning disability would be displayed in some circumstances and not in others. This inconsistent behaviour exhibited by the child was thought to increase stress and anxiety for parents of these boys with learning disabilities. The invisibility of the disorder also 
added to their stress. Mothers and fathers differed in the evaluation of conflicts in their life, as fathers reported increased levels of interpersonal conflict, while mothers were more affected than fathers by the family's crisis.

Interventions aimed at different family members may be of benefit. A pilot project summer play scheme for children with learning disabilities was reported to be a positive experience and benefited all family members, especially mothers (McGill, 1996). This study indicated that while families shared many perspectives on respite care there was variation in what parents wanted, such as scheduling respite to when it is most needed and in ways preferred by each family (McGill). These results were similar to those of Burke and Cigno (1996).

Some work on learning disabilities has been conducted in other countries. Pearson and Chan (1993) found that mothers of children with learning disabilities in one region of China experienced high levels of parenting stress that often went unacknowledged and had less emotional support than mothers of children without learning disabilities. Residential care for these children helped to reduce parental stress. This study suggested that mothers might have very little time to develop relationships outside the immediate family due to full time work or the lack of emotional resources.

There is no question the presence of a learning disability increases family stress. In a follow-up study of parental stress and family functioning, Dyson (1993) revealed that families of children with a disability experienced greater stress compared to those families without disabilities and that this situation did not change as time progressed. Although it was found that parents became pessimistic over a child's future, they had 
concerns over a child's physical and behavioural characteristics, as well as experienced more family and parenting problems during a child's growth. Abnormal family functioning did not always develop and this was consistent with the findings of Dyson (1996), suggesting resilience and adaptation abilities are present.

Information provided to parents about their child's physical or learning disability played an important role in helping parents understand and cope with their situation (Pain, 1999). This study reported that personal communication helped parents cope emotionally and/or empowered them to access support services. Professionals were the most frequent source of information, while voluntary organizations provided advice and support. Parents wanted information to improve management of their children's behaviour. The amount of information can also be overwhelming. Findings with respect to written material suggested that when selecting information, highlighting the most important areas to read was most helpful to parents.

Blumsack, Lewandowski and Waterman (1997) conducted research on parents' responses to questions regarding the development of their children with and without learning disabilities from infancy to around eight years of age. The authors reported that children with learning disabilities experienced more neurodevelopmental problems and /or delays in areas such as gross and fine motor skills, language, as well as, attention difficulties than normal achievers. The most common difficulties noted in children with learning disabilities were with multistep directions, printing letters of the alphabet, and comprehending directions. The authors reported, however, not all children with learning disabilities displayed combinations of the more frequently reported problems. 
The literature reviewed tells us that those mothers / parents of children with a learning disability experienced greater stress and emotional pain when compared to other families. They needed help from various sources to sort out their child's problems.

Supportive and non-supportive relationships were experienced with professionals. It was found that families functioned relatively well in spite of the demands on time and disruptions. Sibling self-concept was not always negatively affected, in fact, some parents indicated that the experience provided growth for siblings and an awareness of the struggle of others. Mothers did find that camps or residential care were beneficial to alleviate stress. Professionals and support groups were frequent sources of information for parents.

Children with learning disabilities experienced various problems before the age of nine. Parents who were not familiar with psychoeducational assessment often discovered these difficulties. This suggests that learning disabilities appear to have developmental indicators.

\section{Learning Disabilities and Siblings}

Research into the effects on siblings of children with learning disabilities suggests other concerns that parents need to address. Brothers and sisters received less attention from their parents because of the additional help required of parents by a child with a learning disability (Burke \& Montgomery, 2000; Dyson, 1996; Glendinning, 1986). Burke's and Montgomery's findings also indicated that siblings contributed and shared in caring responsibilities undertaken by parents. The authors indicated that sibling support 
groups were viewed as positive experiences for children not having a learning disability, and families benefited from their child's participation. Sibling support groups were also suggested in Dyson's study.

Sibling relationships were reported to be mostly positive. Children without a learning disability were understanding and patient with their brother or sister with a learning disability (Dyson, 1996; Waggoner \& Wilgosh, 1990). Some parents, however, indicated feeling guilty for giving more time to their child with a learning disability, and were consequently concerned about the display of inappropriate behaviours sometimes observed in their other children (Dyson).

Evans, Jones and Mansell (2001) conducted research on the development and evaluation of sibling support groups that were created to help brothers and sisters consider their relationship with their sibling having a learning disability. The authors found that children without a learning disability had enhanced self-esteem, increased knowledge about learning disabilities and associated behaviours, and were more involved with their siblings at home due to their participation in such a support group. Parents also noted that relationships improved among family members at home as a result of their children's involvement in such groups.

While there has been very little focus on siblings of children with learning disabilities, studies that included siblings and their parents have provided some insight. The findings revealed that siblings are often affected by having a brother or sister with a learning disability, but the nature and degree to which they are affected are largely unknown. Siblings assisted their parents in caring for their brother and/or sister with a 
learning disability. The needs of other siblings should be considered when providing support services for any child.

\section{Effects of Learning Disabilities on the Affected Individual}

Mothers of children with learning disabilities experience pressures and concerns stemming from their awareness of the potential risks facing their child. The next group of studies was relevant for inclusion to provide insight into these problems and their significance for these women.

Statistics indicate that $35 \%$ of students identified with learning disabilities drop out of high school, $50 \%$ of females with learning disabilities will be mothers within three to five years of leaving high school, up to $60 \%$ of adolescents in treatment for substance abuse have learning disabilities, and $50 \%$ of young offenders tested were found to have undetected learning disabilities (Washington Summit, 1994).

A higher suicide rate in adolescents is positively correlated with learning disabilities. Almost $50 \%$ of adolescents who committed suicide had previously been identified with a learning disability (LDAC, 2001). Adolescents committing suicide showed evidence of spelling and handwriting deficits in their suicide notes similar to those found in the written samples of adolescents with learning disabilities (McBride \& Siegel, 1997). This suggests that learning disabilities might be an unrecognized risk factor in adolescent suicide. Children and adolescents with unrecognized, poorly treated, or untreated learning disabilities are at a higher risk of developing secondary behaviour 
problems and psychiatric disorders than those children who have received interventions (Silver, 1989/1993).

Adults with learning disabilities lacking necessary education manage to keep a job only up to three months because of poor social skills rather than skills related to the job, and $30 \%$ of adults with literacy problems were found to have an undetected or untreated learning disability (LDAC, 2001). The most common long-term condition suffered by children up to fourteen years of age is learning disabilities (LDAC).

Other high risk behaviour has been found among this population. A recent study by Beitchman, Wilson, Douglas, Young, and Adlaf (2001) comparing adolescents with and without learning disabilities, found that those adolescents with learning disabilities are at increased risk for developing substance use disorders.

Sitlington's (1996) review of studies on the adjustment of adults with learning disabilities recommended the need for emphasis in education on life skills and supports necessary for successful transition from one environment to the next as an individual moves into adulthood. While employment and post-secondary education are important, the focus for any student receiving special education services should be on adult roles such as maintaining a home and appropriate community involvement, as well as, on satisfying personal and social relationships.

In a U.S. study, less than half the numbers of young adults with learning disabilities were employed in skilled work requiring specific training; the majority were working in unskilled, entry-level jobs which provided few if any benefits and little chance of advancement (Foruqurean, Meisgeier, Swank, \& Williams, 1991). This study 
suggested that the emphasis for children with learning disabilities should be on ensuring that they obtain optimum mathematics skills before leaving high school, experiencing employment during the high school years, and actively involving their parents in their education.

Not all children with learning disabilities have psychiatric disorders, severe behavioral problems, and/or substance use disorders. They are, however, at risk for developing these if the disability goes undiagnosed and if related problems are not recognized and addressed. These children also need to be prepared for the adult world for full participation in their community.

\section{Summary of Reviewed Literature}

There is very little information on the experiences of mothers having a child with a learning disability and the effects of this experience. The studies reviewed revealed, however, that mothers / parents / families experienced stress, and the source of that stress was not clearly defined. Mothers needed outside help and resources to deal with a child's problems and a lot of time was spent helping a child, often to the detriment of themselves and other family members. Mothers also experienced frustration in not being able to get a diagnosis in a timely way and in the slowness of systems to respond to their needs.

While learning disabilities are usually not identified in the pre-school period, there are signs during this time that may indicate a potential problem. Concerns and uncertainity over the future of their children, as well as, children's lack of preparedness 
for the adult world were discussed. Mothers assumed a variety of roles, the most important one being an advocate.

Statistics indicate that mothers have good reason to be concerned about their children with learning disabilities. These mothers want to prevent outcomes such as substance use, suicide, involvement with the justice system, and mental health problems. They understand that an education is essential for success in the adult world. Mothers, therefore, are aware of the need for learning disabilities to be identified and interventions established early in a child's development to prevent serious problems from developing.

Limitations in the studies reviewed included the selection of families may not be representative of the general population. A lack of comparison with families having no children with handicaps and a lack of replication studies was noted. Very few studies dealt exclusively with mothers and their experiences of having a child with a learning disability. Some studies focused on one or both parents. It was observed that most of the studies had boys heavily represented in their samples. This could be due to the fact that the incidence of learning disabilities in the general population tends to be higher in males.

While the literature selected for review provided insight into learning disabilities, further research is warranted to better understand mothers' experiences. It is hoped that the current research will contribute to that understanding. Phenomenological research enables us to get at the experience "as lived" thus providing valuable insights. 


\section{CHAPTER 3}

\section{METHODOLOGY}

This study is guided by phenomenology especially the human science approach of van Manen (1997). It is designed to explore the meaning and significance for a group of mothers living with a child who has a learning disability and describe their experiences. The first part of the chapter presents a discussion of phenomenology as a methodology. The second part provides the steps in the research method used to explore the experience of mothering a child with a learning disability.

\section{Phenomenology as Methodology}

Phenomenology is the study of the life world, the everyday existence, and provides insight and deep understanding of the nature and/or meaning of everyday lived experience ( $\operatorname{van}$ Manen, 1997). The objective of phenomenology is to explore the lived experience of others. Phenomenology as a method of inquiry in nursing brings into language perceptions of the human experience. Since nursing practice is involved in people's lives and experiences, phenomenology is indeed an appropriate method of research.

The aim of phenomenology is to describe that lived experience of everyday life, an individual's life world. In order to achieve this objective, phenomenological research "borrows" other people's experiences, and their reflections on these experiences to arrive at an understanding of the meaning of that human lived experience (van Manen, 1997). 
This borrowing of others' experiences allows us to become more experienced ourselves. This experience is "transformed into a textual expression of its essence in such a way that it is a reflexive, reliving, and a reflective appropriation of something that is meaningful" (van Manen, p. 36). This insight is necessary to accurately reflect, clarify, and make clear structures of the meaning of the lived experience. To study lived experiences and everyday meaning, phenomenology asks a very natural question, "what is the experience like", bringing researchers in greater contact with a person's life world. To explain phenomena human beings must be aware of and conscious of their world. Consciousness is the only access humans have to the world, therefore, people are already related to the world (van Manen). Intentionality, a fundamental concept of phenomenology, denotes "the inseparable connectedness of the human being to the world" (van Manen, p. 181). Intentionality is retrospectively available to one's consciousness. An individual, therefore, cannot reflect on a lived experience while living it. As a result, phenomenological reflection on lived experience is already passed and recollective (van Manen).

Phenomenology, a study of essences, strives to uncover and describe structures or internal meanings of lived experience (van Manen, 1997). The essence is "that what makes a thing what it is, without which it would not be what it is" (van Manen, p.177). Essence, therefore, is revealed through intuiting or accurate interpretation of what is meant in a particular description, providing common understanding of the phenomenon, and described in language. When the essence of the experience has been described and interpreted into language, it provides a fuller significance of that experience and its 
meaning in the everyday existence or life world (van Manen). Phenomenological description is something that can be recognized as an experience that someone had or could have had.

Phenomenological reduction, another core concept of phenomenology, refers to returning to the original awareness of a phenomenon being studied. Reduction starts with withholding beliefs, assumptions, and biases about the phenomenon. Complete reduction may not be possible due to an individual's relationship with the world. The only way to see the world is to remain as free as possible from preconceived ideas about the phenomenon. Therefore, for reduction to be successful, the researcher identifies ideas, knowledge, and/or beliefs about the phenomenon. These ideas are separated out of the consciousness, referred to as bracketing. Bracketing helps the researcher get a purer description of the phenomenon under study (van Manen, 1997), but may not be always possible due to one's presence in the world.

Phenomenology as a human science is used to study the structures of meaning of the lived human world (van Manen, 1997). Phenomenology articulates through the content and form of text the structures of meaning embedded in lived experience (van Manen). Making something of a text or of a lived experience by interpreting its meaning is more accurately a process or insightful discovery of "seeing" meaning (van Manen). The researcher reads the text as a whole to become familiar with it. Thematic analysis "refers to the process of recovering theme or themes that are embodied in the evolved meanings" (van Manen, p. 78). Phenomenological themes are experiential structures of the experience captured in singular statements within a text and evolve from analysis 
(van Manen). Once themes have been identified the art of writing and rewriting commences. These acts of re-thinking, re-flecting, and re-cognizing help to create depth, provide layers of meaning, and goes back and forth between the parts and the whole, to end up with a text that describes the phenomenon without losing the richness of the data (van Manen).

\section{Research Methods}

\section{Research Design}

Methodological interpretation by van Manen (1997) was selected for this study to describe the lived experience of mothering a child with a learning disability. The objective for the study was to understand what being a mother of these children is like.

This part of the chapter describes the research methods. This section relates participants, criteria for participation selection, data collection, setting, data analysis, ethical considerations, and credibility.

\section{Participants}

My initial research plan was to study parents' experiences of having a child with a learning disability. I was interested in both mothers' and fathers' experiences and attempted to recruit them. Most of my research material reflected parents. When I began my recruitment of potential participants, however, only mothers responded expressing their desire to participate in this study. Maybe this is indicative of the way mothers 
assume responsibility for dealing with their child's learning disability or they may be more willing to discuss their feelings and experiences.

\section{Criteria for Participant Selection}

Purposeful sampling was used in this study. Individuals selected for participation were based on their particular knowledge of the phenomenon for the purpose of sharing knowledge (Streubert \& Carpenter, 1999). Criteria for participation were as follows:

- The parent would have a child with an identified learning disability;

- The child could be in primary, elementary, secondary, and/or post-secondary education;

- The parent would live in and around the St. John's area.

The Executive Director of the Learning Disabilities Association of Newfoundland and Labrador (LDANL) was approached to facilitate recruitment of participants (Appendix A). Ten mothers were recruited in this study. This number was considered adequate since sample sizes in qualitative research are usually small because of the large volume of textual data that must be analyzed (Sandelowski, 1986).

The Executive Director asked potential participants permission for me to contact them to explain the study, and to obtain their consent for participation prior to the initial interview. This contact helped to prepare the participant for the interview, facilitated response to any questions and/or concerns regarding confidentiality, informed consent, and taped recordings. This also provided additional time for participants to formulate any other questions prior to the actual interview. Five participants were recruited through the 
help of the LDANL. The remaining five participants in the study volunteered to participate when they heard about the study from others. Upon permission from these volunteers their names were passed on to me for contact. These people were contacted to provide them with an explanation of the purpose of the study and to confirm their willingness to participate. I provided them with all the information given to other participants and responded to any questions. All of the participants had children with an identified learning disability.

\section{Data Collection}

Participants were asked to describe what is like to be a mother of a child with a learning disability. Face to face interviews provided the participants with the opportunity to fully explain what this was like and to describe their experiences. The purpose of an unstructured interview format was to allow for greater range in answers. I asked openended questions, such as, tell me what the experience is like. This type of questioning indicates that there is no set response and a participant is able to talk more freely about the experience of mothering a child with a learning disability. The time frame for data collection was five to seven months. Demographic data were obtained from the participants at the time of the interview to provide a description of those who took part in my study.

Participants were advised that their involvement would consist of two interviews lasting up to two hours each. These interviews were audio taped. Tapes were transcribed verbatim as soon as possible after the interview. The length of the first interviews ranged 
from one hour to one hour and forty-five minutes. Interpretative summaries were made from the transcripts and a second interview was conducted about two to three months after the initial one. This time frame was necessary to complete the transcription of the interview and perform the preliminary analysis. The purpose of the second interview was to review with the participants the interpretative summary, clarify responses from the first interview, examine any other areas arising from the data, as well as, to verify and confirm findings. This latter activity assisted with validity of the interview data. These interviews lasted about thirty to forty-five minutes. All mothers agreed that the interpretative summaries were an accurate reflection of their situations.

\section{Setting}

Some participants were interviewed in their homes. Other interviews were conducted at another location arranged by the researcher upon the request of the participant. Consideration of time, place, and comfort for participants was thought about ahead of time to increase the likelihood of sharing experiences. I carefully listened to the participants to encourage fuller description and rephrased statements as necessary to produce description that would provide a better understanding of the participants' lived experiences.

\section{Data Analysis}

Analysis of the data began at the completion of each interview. Hermeneutic phenomenological reflection was used to capture the essential meaning of mothering a 
child with a learning disability. This process requires reflection and clarification to understand the structure and meaning of the lived experience (van Manen, 1997). To capture this meaning the specific approach used was the selective or highlighting approach. In this selective reading approach the text was read several times and statements that seemed to illustrate the phenomenon were underlined or highlighted. These highlighted phrases and/or sentences provided the basis for me to capture as completely as possible the meaning conveyed in the material.

Transcripts were read and reread. I met to discuss themes with my thesis supervisor. Themes were compared in each interview looking for commonalities and differences, as well as, to identify overall themes that best describe what it is like to be a mother of a child with a learning disability. When themes were identified, the process of writing and rewriting (hermeneutic analysis) was done to show their interrelationships. Rewriting continued until I felt the themes (parts), and relationship between themes (whole), accurately captured the way mothers felt about their experience. Writing, rewriting, rethinking, reflecting, and recognizing is necessary to acquire fullness of the experience of that life world (van Manen, 1997).

\section{Ethical Considerations}

The purpose, procedure of the study, and the expected duration was discussed with participants. Informed written consent was secured from participants to tape interviews and to use the information obtained from the study. This informed consent was obtained at the initial interview (Appendix B). Participants were advised of their right to 
withdraw from the project at any time. Permission was obtained from the Human Investigation Committee to proceed on this basis prior to commencement of the study (Appendix C).

All forms, tapes, and transcriptions were coded to assure confidentiality. A $\log$ of names and corresponding codes was kept in a locked file accessible only by the researcher. This list was kept separate from the recorded audiotapes. These tapes were kept locked in a separate location and will be destroyed at the end of the study. Paper transcriptions will be kept for five years (Integrity in Scholarly Research, 2001).

Scientific merit of this study provides insight for nurses, educators, and other professionals who work with mothers of children with learning disabilities. For ethical consideration, I followed the guidelines in the Tri-Council policy statement (1998) for conducting research with human subjects.

\section{Credibility}

To achieve rigor in qualitative research, credibility was the strategy used. Accurate representation of the participant's experiences is the goal of rigor in qualitative research. Credibility of findings is confirmed when participants are able to identify and validate the findings as faithful descriptions of their experiences (Yonge \& Stewin, 1988). Credibility is also achieved when description and interpretation of an experience can be recognized as experiences or possible experiences (van Manen, 1997). Bracketing was used when I put aside my knowledge and beliefs about learning disabilities to get as clear a description of the mothers' experiences. In this study credibility was achieved by 
consulting with nurse researchers acquainted with phenomenology. Collaborating with my thesis supervisor helped to determine and clarify meaning in the text. Collaboration with participants at the time of the second interview helped to ensure verification when participants indicated that the interpretative summary accurately described / represented their experience. 


\section{CHAPTER 4}

\section{FINDINGS}

What it is like to be a mother of a child with a learning disability? This chapter is an exploration of these women's experiences as mothers. This chapter is divided into two parts. The first part gives a brief description of the participants. The second part focuses on the themes derived from the interview data. The themes, presented in no order of significance are: searching for answers, easing the child's struggle, need for assistance and understanding, no time for self, isolating and lonely life, and an uncertain future.

\section{Participants}

Ten women agreed to be interviewed for this study. Only a few demographic details were collected from these participants. The research was conducted with many participants who were in a position to identify each other and I was careful not to collect or present clearly identifying information. The ages of these mothers ranged from 38-59 years. Educational levels of these women varied somewhat. All had post-secondary education, and most were college / university graduates. Some had graduate degrees. All participants lived in St. John's and the surrounding areas. 


\section{Themes}

\section{Searching for Answers}

Learning disabilities by their very nature are not easily understood and children may not be diagnosed for a number of years. Parents and even teachers, however, know that there is a problem with the child's ability to learn. The first theme identified was that of searching for answers. One of the common experiences of all women in this study was trying to have their child's problem identified so that they could better understand and help the child. All of the women described suspecting a problem with their child in the pre-school years - that is three to five years of age. For a few of these mothers interviewed, professionals were already following or monitoring their children for problems discovered in the first year of life. All mothers described a variety of behaviours observed in their children, such as not wanting to print or not printing well, not being able to give appropriate answers to simple questions, unable to read, no apparent interest in learning the alphabet and/or colours, not wanting to watch children's educational shows, increased activity or low level of activity, and slowness to speak. One participant stated:

When he was little, I couldn't figure out when he was very little, this is pre-school, why he didn't have [any] interest in letters. He would walk away. Like Sesame Street had flashing of the [letter] $A$ and the [letter] $B$... he would walk away from the television when that came on.

And another: 
Getting her to watch like Sesame Street for example, she had absolutely no interest, didn't even want to talk about it ... was never interested in sitting down and playing a game or anything like that.

Mothers indicated they were very concerned about their children at this stage and were uncertain about the significance of the problem because they knew that children developed at different rates. Some women were puzzled about their children's lack of attention given to skills that they knew were necessary for learning and survival. One mother related:

We had her in nursery school for two years and I know they did all this. She didn't know her alphabet, she couldn't read one word, she couldn't, she couldn't. . . so I was really, really puzzled about that.

Women with other children were able to see that the child with the learning disability was not performing as well when compared to his/her siblings at the same age. When some mothers sought advice from professionals regarding observed behaviours, they were told to wait and see how their child progressed and to continue to observe them to see if the problem would resolve itself with time and maturation. A mother described how she was advised:

Every child learns differently, and just let her go about it in her own time [leave her alone and see how she develops on her own].

These mothers noted that the problems did not ease or disappear but became more noticeable and defined as their children entered the school system. As their child grew older his/her abilities fell further behind his/her peers. Areas related to school 
performance, such as ability to print / write, read, mathematics, organizational skills, focus, and attend, are not given a great amount of attention until school readiness is assessed usually between the ages of four and five. One mother found:

When he got into school, I could see, and when I would go to the school and help with his class, and that he didn't seem nearly as interested in certain things as other children. He was more active than a lot of them, and then in grade 1 that's when things started happening, all the other children were reading, and he still wasn't.

All women recognized their child had a problem but found that having the problem identified was extremely complicated, frustrating, and emotionally draining. One participant illustrated:

I knew for a long time that there was something different about this child. I was actively looking for a diagnosis. I knew he had a learning disability long before anyone could confirm that to me. I just had to get somebody to put it on paper and that took a long time.

While some teachers were said to agree there might be a problem, clear identification of a learning disability was not possible without further assessment by other trained professionals. The teachers at times did try and communicate to the mothers some of the problems in school:

By the middle of kindergarten, her kindergarten teacher called me in to say, she still didn't know her alphabet, problems with reversing letters, still couldn't read, couldn't name off all her letters and she thought there was something there, but she didn't quite know. 
Some mothers described conveying their observations and concerns to teachers and/or principals through phone calls and interviews. While it might be agreed that an assessment should be completed, when it was done in school, feelings of disappointment emerged as one woman related:

The person would do a quick study and that would go back to the principal, and the principal would say we did all we could and there's nothing wrong.

Other mothers stated they chose to pursue private practitioners for assessment in cases where the waiting lists in the public system were very long. This approach helped speed up the process of identification and the urgent need to find an answer to a child's problem. This method resulted in families incurring considerable financial cost.

For some of the women interviewed, their child's problem was hidden or "invisible" to teachers and others. This was felt to be the result of how well a child was doing in school. Mothers stated that if their child was passing teachers did not seem to think there was anything wrong. One participant related:

So from the teacher's point of view, he wasn't a problem even though he struggled in areas, he didn't cause enough of a problem to really demand a lot of attention.

While a child may be passing a school year and doing well, an unidentified problem was going unresolved. This contributed to an already existing level of frustration with increased pressure to discover what the problem was, and left mothers wondering "where do I go from here." 
Mothers had hoped that educators would be able to help them understand what their child's problem was, and would have the requisite knowledge from which the specific nature and extent of the problem could lead to identification. As one participant described:

They didn't have a clue, I can't even talk about that one.

At times another woman's concerns regarding her child was all too readily dismissed by a teacher. The teacher would attribute the child's problem to other causes. She was told:

Oh don't be ridiculous, he just wants your attention, or he just wants you to do the work for him, or he just wants you, you know... all these little things, and we'd read [different books, and ask] is it this, is it this, is it this.

All participants admitted they questioned themselves and wondered what was going on with their child. These women described a number of questions that frequently surfaced in trying to figure out what the problem was. Why does this child not learn like other children? Why do things take so long to complete? What is their difficulty in reading and writing? Why is there no interest? Why are things so hard for this child? Trying to sort out the problem was very agonizing for all these mothers. Some felt driven and determined to do something about their child's problem, as conveyed by one mother:

And of course, being Mom, you had to fix everything. That's the big pressure. You have to fix this. This has to be fixed. . you have to do it. 
These women all felt relief when the identification of a learning disability was acknowledged. They also felt satisfaction that their instincts were indeed correct. One mother illustrated her feelings as:

Well it's about time, and thank God, because we know it, [we were] pleased, somebody else realized it too.

For some mothers identification of the problem provided the base necessary to begin securing resources to assist their children to learn and meet grade level goals. Identification also enabled these mothers to search and familiarize themselves with learning disabilities, their causes, what could be done, and how to live with them.

This need to know what their child's problem was continually haunted these participants. They knew someone, somewhere, had to be able to give them an answer, and these women continued to search for this. For these mothers, it was like a puzzle, very frustrating and stressful, unable to find the strategic missing piece that would be the key to everything else. These mothers in their exploration for answers became informed individuals, knowledgeable, able to help, and to be advocates for their child, as well as, willing to guide others in similar situations. Being able to put a name on the problem and being provided with written documentation was very important for all these women.

\section{Easing the Child's Struggle}

A role of a mother is to help a child with any problems he/she has. This role takes on huge proportions for a mother with a child who has a learning difficulty. Another prevailing theme was that of trying to ease the struggle for the child. All mothers were 
profoundly affected by the extraordinary struggle they observed their child with a learning disability experience in coping with various aspects of everyday living, and tried to find ways to ease their child's situation.

These women felt compelled to provide for the special needs of their child as a result of careful observation of the child's strengths and weaknesses. While watching a child struggle is painful, it was an essential part of these mothers learning to understand a child's needs, provide effective interventions, and advocate on their behalf. One woman stated:

It pulls a depth out of you, you don't know you have, and a compassion for struggling children in a way that, unless you've had a struggling child, you don't know what it pulls out of you.

And another:

I mean it really has a major impact, which is not easy for casual observers to notice, but it's there, it's there all the time.

The most common struggle expressed, and an overwhelming challenge for these women, was dealing with the demands of school and especially homework. These women indicated employing different strategies to help their child with homework. Common practices in the approaches used were the need for repetition, breaking assignments down into manageable tasks, providing breaks, showing patience, and understanding. They also tried different ways of interpreting information for their child, helping to provide organization and structure, simplifying materials, developing shortcuts by providing tools and aids, as well as by sharing in reading and writing tasks. All mothers constantly 
looked for new insights into their child's problems, as well as, for advice and techniques that could assist in making life easier especially in completing homework.

One way to ease the child's struggle was to understand the material their child was learning and the way in which it was being taught. This often required co-ordination with the school as well as reading and preparation. A not uncommon experience described was:

We have to actually sit down, and do her study notes for her, go over things with her, read the books ourselves, read the chapters ourselves, so we'll have an understanding.

One participant indicated having difficulty in adjusting to different teaching styles and expressed frustration that one teacher is doing things one way, and another is teaching a different way. While there was not a great deal that could be done about this, different styles became problematic when reaching junior high and high school. At these levels a child had a different teacher for each course requiring these women to intercede and consequently spend additional time helping a child understand the material.

As children progressed through school, some participants found they were increasingly challenged to understand the material. It became a family affair. In some instances fathers assisted with certain subjects where their aptitude was greater. Another sibling helped with completion of assigned work when these women were required to pick up other family members, and/or seemed to need a break from a homework session.

Many families hired tutors to provide instruction in some subject areas. The use of tutors was expressed as invaluable in dealing with difficult subject matter, in providing mothers with time to help another child with homework, or complete some other job 
related to home and/or their own work. Those women using tutors indicated the cost was very high and posed a significant financial burden on their families. One mother noted her frustration because of the frequent turnover in tutors and her child's difficulty in repeatedly having to adjust to new people. This situation resulted in both parents assuming full responsibility for the homework.

Even with the support from family members and paid tutors, these women assumed an overwhelming share of the responsibility for helping their child and coordinating the involvement of others. Each mother effectively became an in-home counterpart to the classroom teacher. This role required an enormous effort and commitment of time by these women - often to the detriment of other aspects of their lives. At the same time mothers wondered if their efforts were really helping, especially when there was no conclusive diagnosis of their child's problem.

The daily process of doing homework for mothers was long and drawn out, often an arduous experience filled with frustration and other strong emotions. Mothers reported feeling tired, exhausted, and drained by the experience:

If the parent takes the responsibility, you know, set a time and help the child do the homework, then you can have, you know three hours. . . on Saturday, and then you're completely worn out, you don't. . . and then Sunday, you know, you got to get up and go through it all again because the homework [has] got to be done.

There were some areas in which mothers felt powerless to help. These women could only observe and feel concern for the time their child needed to complete homework, inability to make and keep friends, lack of involvement in outside activities, 
and loss of free time. While some indicated their child was involved with the scout and guiding movements, they were watchful for problems, arranged for movie nights and special birthdays to provide opportunities for time with same age peers.

All of these women interviewed said they were constantly trying to raise their child's confidence and self-esteem. Part of this effort was aimed at helping their child understand the nature of the problem and find approaches to help them deal with their difficulties:

It's a constant struggle to build up her confidence, because things always happen where you know, to kind of knock her down.

Effort to ease their child's struggle led some mothers to seek professional advice and counselling for their child, show a video on learning disabilities to siblings, and attend support group meetings. One mother found out about famous people with learning disabilities and told her child about them. She tried to illustrate to her child that she could also overcome her difficulties and be a success. When her child became overwhelmed, she arranged for her to meet with another child with a learning disability to talk over problems and share experiences. As this mother related, it was also helpful to her.

These women worried and expressed concern about their children's daily struggles and tried to do something. They experienced the emotions felt by a child when a test was failed or passed, when excluded from events, and then left to provide explanations as to why this happened. There is a special bond and a closeness that exists between these mothers and children. They both experience the tears, frustration, and 
triumphs that only can be captured by sharing that lived experience. One mother's comments portrayed the depth of that concern:

I think I'll always be concerned about [my child with a learning disability] . . . until the day I die. I will always be concerned about him.

\section{Need for Assistance and Understanding}

Another theme underlying all mothers' experiences was the need for assistance and understanding of their child's problem by others. These women admitted they could not deal with this problem by themselves. They wanted and looked for guidance, help, and resources to deal with and support their child from the time a problem was first suspected / detected through to the point when they would be independent adults. Mothers indicated they were not familiar with learning disabilities prior to this, and so did not have the knowledge that would help them know what to do. This need for assistance required these women to be actively involved in their child's life, especially, in the child's education.

One of the first challenges in this regard was finding out what sources of information and resources are available to provide help. This was often complicated when there was no clear diagnosis of a learning disability, and if problems observed could be attributable to other conditions or behaviours such as attention deficit disorder. It was difficult, therefore, for these women to identify appropriate forms of assistance if the nature of the problem was in doubt. Access to some support systems is conditional upon having a clear diagnosis of a learning disability. One participant explained: 
It's not easy, dealing with systems and trying to get help.

Some women realized shortly after they had begun looking for help with their child's problem that it was difficult to find a central source of information and guidance. Each mother, consequently, had to rely largely on her own resourcefulness to identify, investigate, and secure such information.

These women expressed many problems associated with getting the necessary help / resources that were frequently complicated, involving a lot of time and effort. In fact, some mothers indicated feeling so strongly about their situation they became vocal advocates to get the help they needed. All mothers felt that without their direct involvement and perseverance as advocates, their child could easily "fall between the cracks" of the existing systems and become lost.

The need for assistance and understanding was evident in the mothers' experiences with the educational system. Negotiating the educational system was another challenge described by all mothers. Negotiating in this context meant both navigating the path to find help and resources, as well as discussion and compromise to ensure that the help provided is appropriate, realistic, and effective. Some mothers expressed the opinion that failure in the educational system hindered the process of identification of a learning disability. As one participant explained:

You meet a teacher who would really want to help, but seemed like it was beyond her, she would have to pass you on to someone else and that person would let you down.

All mothers felt that the onus was constantly on them to bring their concerns and issues to the forefront and to instigate action. For one mother: 
If [you] don't ask for things, nothing will ever be handed to you ... nothing. There's really no support, only [what you do for yourself].

All mothers expressed varying degrees of frustration when trying to get assistance for their child. One participant indicated:

We could have an interview for ten hours . . . [and] I could start to tell you.

While most of the focus was on their personal situations and the needs of their own child, these women felt compassion for others and they hoped their advocacy efforts might benefit other women and their children with learning disabilities. This reflected the degree of feeling and depth of concern experienced. For one mother the desire to fight for struggling children was a passionate one:

I just want to try to see it [school system] changed, so everybody doesn't have to struggle and fight for services.

For some women efforts were not necessarily limited to a particular classroom or the school. Some indicated that it became necessary to deal directly with the school board or even in extreme cases the Provincial Department of Education. One participant explained:

They fought against any supports . . . so I had to go all the way to the school board to fight for that.

Desperate for help and to understand the nature of the problem, as well as, the type of resources needed, these women searched for information using libraries and in 
recent years the Internet. They sought advice from anybody and everybody with knowledge and experience in this area, including professionals, as well as other mothers:

I went on the Internet and got reams of information.

As a result of their efforts these participants became more knowledgeable than many teachers regarding interventions and supports necessary for a child's needs. Some mothers indicated they took the lead in the school setting:

... if there's a meeting, if we have a meeting, I chair the meetings, because I find that at least I can cover and I know what needs to be done, and I know what I want for my child.

Interaction with the school system for these women focused in a number of other distinct areas. While getting an identification of a child's problem was a critical piece, discussion of appropriate interventions and supports, monitoring how these were working, and co-ordinating the exchange of information with professionals outside the school system was also required.

All mothers interviewed indicated spending a great deal of time talking with their child's teachers and discussing school performance. Some women's experiences were positive with teachers when both parties were able to see the problems and work together in harmony:

He had a teacher who was so understanding, who spent extra time with him, who gave him a lot of leeway. 
For some mothers, junior high school enabled them to experience hope and support with some relief in their daily struggles, even when an identification was unconfirmed. One mother conveyed:

We started getting teachers who seemed to have ... but the teachers were individually helping him and were sort of saying well, we'll go ahead and do this and you do this, you know or whatever.

While another stated the junior high school principal's response to her situation and that of her child reflected interest and compassion:

Like I'm here to help you, if there's anything we can do, we'll do it, we're not about putting up blocks, we're about taking them down ... and the years in junior high were really supportive because of her [principal] and a really good guidance counsellor, and I can't thank them enough.

The confirmation of a learning disability is intended to provide greater insight and direction to teaching staff regarding the nature of a child's problem, as well as, their needs. It also served to focus the mother's efforts. The greatest difficulty for these mothers was trying to understand why interventions and/or supports seemed at times impossible to be put into place. One mother indicated becoming very frustrated when others challenged arrangements:

Somebody would read the test to her, and she would do really well, right and teachers in school questioned that, that sort of stuff, it was a bit of a battle.

These women indicated that getting supports put in place in a timely manner was critical for success. At a time when frustration was high for mothers and their children in 
terms of academic success, having to wait for these issues to be worked through and arrangements made was stressful. These women became totally dependent again on others in the system to make things happen. Yet while progress was being made, the slowness of the process within the school system was reported to be disappointing.

Some mothers explained that when the agreed upon supports and resources were put in place, they needed to constantly monitor how well these were working. If, for example, arrangements were made for their child to get copies of notes from a peer because note taking was problematic, these women felt they had to constantly check to confirm that this process was working. A child and/or the teacher could not be depended upon to take notice when the process broke down or to take remedial action. A minor breakdown of this nature had major consequences, such as, on preparing for upcoming tests. There was always something to be done to make sure things ran smoothly, and the need to be vigilant as expressed by one participant was a common experience:

... and then at certain times you meet [with teachers] and you ask for certain supports to be put in place. But things had been forgotten or peer notes she's supposed to get that ... that falls through, these are the things on a daily basis I got to keep checking [on].

I sound like a watchdog, but I got to be and then there are so many changes...

All mothers experienced new teaching staff as their children moved through the school system. Changes were seen at the administrative level at the individual classroom level and in crucial areas such as guidance counselling. These women felt obliged to meet with new administrative staff and individual classroom teachers with each transition to 
familiarize them with their child. This was considered vital to make sure there was awareness, continuity, and consistency in providing supports and resources their child needed. While this response was usually positive, there was always a degree of new negotiation involved influenced by the backgrounds, capabilities, and personalities of the individuals. One mother stated:

Now I feel I've got to get [my child] familiar with her [the guidance counsellor], familiarize [the guidance counsellor] with her [my child], and all her needs, even though it will be passed on at the school, but still as a parent, I still have to go in and ensure that it is.

Women who arranged for professional services outside the school system, such as occupational therapy, speech therapy, and psychological counselling, perceived it was necessary to convey important information between teachers and these other services to help their child's situation. Since mothers accompanied their children to these appointments, they were fully aware of the nature and goals of these services as indicated by one mother:

So co-ordinating everything, everything is always up in the air, you kind of co-ordinate it all together.

Mothers found themselves in a strategic position as one woman conveyed:

There are a lot of meetings involved. You have to learn to advocate with systems that may not be responsive, either because they do not understand, or because they don't have the money. When you are advocating for you child, you have to gather data and be prepared to present your information, explain what it is he needs... why he needs it, and fight to get [it]. 
Mothers expressed having to be well organized when looking for services for their child. These women had to make sure current assessments and reports were available when meetings were held. This planning ahead saved some time and was necessary when trying to get help for a child. As one mother described:

I was the only person who had all the data and could organize the meeting and circulate all the documents, so I spent a lot of time on that.

Most interactions with school staff and others were scheduled during normal working hours, sometimes after school. This frequently conflicted with the work schedules of mothers and necessitated juggling these schedules to make time available. Mothers and their families also had to be flexible in their home schedules to accommodate these meetings and related activities as one mother conveyed:

\section{I'm always working around appointments.}

All mothers felt passionate that ongoing effort aimed at securing and maintaining assistance and understanding was essential for dealing with their child's problem and for success.

\section{No Time for Self}

Helping a child who has a learning disability is all consuming. A fourth theme identified as part of these women's experiences was not having any time for themselves. All mothers described getting and providing help for their child consumed a large part of their daily lives. When asked what is the experience like to parent a child with a learning 
disability, participants indicated it was "very time consuming", "it never goes away", it's never ending”, “it's very challenging", "it's very frustrating”, "it's very difficult”, or “it's extremely stressful". This clearly indicates the profound effects the experience had for all these women:

It's like nothing I've ever experienced' it's frustrating, confusing ... there's so many words I could use. It's just so ... it's never ending.

All mothers were involved in running a household, caring for other family members, and most were working outside the home either in full or part-time capacity. These many responsibilities, in addition to the special demands of their children, as well as, the requirements associated with the role as chief advocate assumed by these mothers, required a huge amount of time, leaving very little time for anything else. For one participant her experience was so overwhelming she said:

\section{I did very, very little outside him . . very little.}

One of the greatest demands on the time of these mothers was that of homework. This task invariably consumed most of the entire evening - every evening - as well as a comparable amount of time on weekends leaving little or no time for other activities. For one mother:

Your life is surrounded by her. . . you can't say that you're going to do something because she's got to do homework. she's got homework every evening.

One mother indicated she spent more time on homework with her child with a learning disability than with her other two children combined, while being thankful the 
others did not have this problem. If there was any time left over, many mothers spent this time in preparing their child and themselves for the next day's demands. Weekends for these women often were used as extra days for review for upcoming tests, to organize project work, opportunities to catch up on the past weeks work, and/or to get a start on the upcoming week. These women felt that the success of their child was dependent on their level of effort and commitment. One mother indicated that she could not even think about going out with her spouse during the week:

... [we'd] consider ourselves to be irresponsible if we [went out] when we knew she had homework.

Spending time meeting with school professionals discussing their child's situation and needs, as well as, negotiating the provision of supports / resources that had to be tailored for their child consumed many hours of time. Mothers felt that meetings with principals, teachers, and guidance counsellors were critical once a learning disability was identified. These meetings were also required at strategic times during the school year to assess progress outside of the regularly scheduled reporting periods. The need to be available to meet with key people was necessary and often had an effect upon work schedules. One participant stated:

Last week I had a one hour meeting with the teacher and the principal. I got to meet with the principal again now, once I set it up. It's just I'm constantly off work. If I had the kind of job where you had to punch a clock, I mean, I wouldn't be able, I wouldn't be able to do it.

Mothers assumed these responsibilities out of love and caring for their child, and sometimes an underlying sense of guilt that they may be somehow responsible for their 
child's problem. Mothers indicated feeling an emotional impact from their child's situation, as well as, the strains and frustrations that it placed on all members of the family. Only one mother indicated that emotional and behavioral difficulties of her child caused great disruption in the family.

A major source of these strains and frustrations was the imbalance in time and effort mothers had to devote to their child with a learning disability compared with other family members. Some women described that they were at times not able to meet the needs of other family members, and recognizing there was very little they could do about this situation, they felt challenged themselves. As related by a mother:

It's hard to be supportive when people don't think the support is warranted. That is even harder. Why are you doing this? You're constantly being questioned.

All mothers found that it was important to be highly organized in their own lives to ensure that sufficient time was available to accommodate their commitments to support their child with a learning disability. While most women would like to see their lives less regimented with more flexibility and freedom, organization was essential for the success of their children. This organization included their households as well. These participants indicated that their children needed help with organization. Structure was necessary for daily functioning and survival. Even with meticulous thought given to organization, there was no extra time: 
We have to be extremely organized to make up for her. We have to do the thinking for her a lot of the time, and that's the only way. If I forget about one or two subjects for a week, the whole thing turns into chaos. If we are disorganized there's no hope for her. It's added a lot more stress to my life.

Some of the reasons why the women had no time to themselves was the need to organize and transport other children to their activities and arrange family schedules to effectively prepare for each evening and a child's homework. Many creative strategies were developed, such as prioritization of homework assignments and determining what assigned task could be successfully completed, while waiting for another child engaged in some after school activity. Recruiting and organizing time for tutors required careful scheduling and attention that consumed more of her time. Depending on the assigned work for any evening, communication with the father requesting his expertise and input into the subject area was also necessary.

Socialization time is considered therapeutic in terms of stress relief. Being in contact with others is important for adults. Most mothers described that they had no time for scheduled social and leisure activities due to the extra demands on time and the level of effort required. Some women described that because their time was restricted, they engaged in more family activities rather that pursuing something on their own. Any activity they elected to take part in would be chosen with consideration of their child with a learning disability. 
Time to maintain contact with friends for one mother was an impossible task. The requirements of work and the additional parenting responsibilities consumed a huge amount of time:

My [particular work] and my family, that seems to take up all my time, there is no time left over for anything else. That's the way it is you know.

These women indicated that the demands on time made them feel very tired and exhausted. All mothers experienced some degree of stress over their situations. This tiredness prevented one mother from participating in social events even when they were available to her:

And I . . used to be really tired. And when things would come up to go somewhere, I was emotionally exhausted too . . . and very seldom did I do it because I never had the time. When I had the time, I was too exhausted.

Some mothers interviewed had to take time off work because of stress and the impact their particular situation was having on them. The experience for all mothers left them feeling overwhelmed from time to time as one mother related:

So, it makes, it really, really difficult, and some days you just want, you say I don't want to do this any more, so . . . [it consumes] a lot of energy you know, and just your mental health and what have you, you usually get worn down.

All participants were sensitive to the actual and potential needs of the child with a learning disability. This was reflected in their perceived need to be available to their child whenever he/she needed to talk about his/her problems, to help with homework, to be 
available after school to make sure homework was written down, and that the child had books to do the homework. This sensitivity limited involvement in activities because of the uncertainity of not knowing when she would be called upon. Some of the concerns mothers had were reflected in this statement:

I was reluctant to go away for any great length of time ...I always felt . . there was a vulnerability . . a and I guess, $I$ sort of maybe was hesitant to leave him too long without being sure that, that everything was okay with him.

And another:

I didn't know why I had to sit with him. I knew there was something in me that told me I had to sit and direct this child.

For some women, being available meant being physically near, or accessible to their child during and/or after school, to be able to talk either by phone, or perhaps visit to alleviate frustration, and provide reassurance to help their child get through the day. While not having time for self could be viewed as a negative, it was considered a necessary part of being a mother of a child with a learning disability.

\section{Isolating and Lonely Life}

People's lack of awareness of learning disabilities and not having the support of others contributed to loneliness. A fifth theme reflected in the experiences of these women was how isolated and lonely they felt at times. They felt alone in their struggle to find help for their child. This feeling arose from the fact that these women were the only ones who truly appreciated and realized the depth of their child's problems, as well as, 
the magnitude of their daily struggles. Seeing the situation through a mother's eyes, feeling the emotion and pain is difficult for the casual observer. They indicated that others did not have an awareness of what was required for a child with learning disability to achieve success academically or otherwise:

Unless you live it, people don't understand.

These women all felt the need to share their story with someone else, even if that person did not understand the problem completely, but was willing to sit and listen. This sharing was observed in the interviews as mothers freely related their experiences to me. When other people appeared concerned and to care about their situation, many mothers sensed that friendship or politeness prompted this interest rather than insight and empathy. Unsure if people really and truly understood their anguish, mothers felt distant from other people. One mother's experience was:

I have a lot of friends and some of them have no idea about learning disabilities, some are very receptive to learning about it, some are not.

These women realized that some people are generally not able to understand and identify with individual situations, anticipate, and/or provide help. They accepted that people are not able to comprehend the scope, limitations, and pervasiveness of learning disabilities in all aspects of life:

When you actually experience something first hand, like having a child who's different, you really do get a better understanding, like you can read all the books you want to, but when you're living it, you really know what it's like to go through it ... [and] the struggles that other people have to [experience]. 
This difference in comprehension was a major barrier separating mothers from many people including friends, and even some family members. One participant described:

I felt isolated from friends and family.

And another:

The inability to not have someone to share your concerns and to empathize with contributes to loneliness and isolation.

Feelings of isolation also arose in dealing with professionals such as teachers / educators. The expectations of these mothers was that all teachers were well versed in and/or had awareness of the magnitude and scope of learning disabilities. It was thought that these people would be knowledgeable about learning disabilities, the needs of these children, and how classroom situations may affect children's lives and that of their families. These women were looking for confirmation, collaboration, and working together in a partnership between home and school. This, however, was not always the case. In some instances these interactions tended to be more adversarial than collaborative, taking on an "us" versus "them" posture. This increased their feeling of isolation leaving participants bewildered and wondering why there were so many obstacles that prevented getting help for a child. One woman stated:

If you don't have [administrators and guidance counsellors] believing and supporting you, you really got a big job ahead of you. 
All participants derived support from others going through the same experience. Mothers needed to confirm their struggle. It is not uncommon for people to seek out others in similar circumstances. These affirmations helped confirm that others shared the same experiences, feelings, concerns, and worries. For one mother:

Sometimes you feel you're really alone and you don't think you're going to make it, and you hear somebody else's struggle which is probably even worse than yours, and you kind of pick up and go on, you reach out to help them, it's not easy, and but it's only through talking to other parents who have [children with] learning disabilities [that you] really understand, cause most of your friends never really, really know what it's like.

Women who took advantage of support group meetings and talking with the Learning Disability Association believed they were valuable resources. Meetings provided a forum to meet others in similar circumstances, to acquire new insight through knowledgeable guest speakers, and to share experiences through face-to-face discussion. Interactions with other mothers served many purposes, such as sharing information about existing resources and how to access them, exchanging strategies that have proven successful in helping their child with a particular disability, providing meaningful positive support, and alleviating feelings of aloneness. These occasions also fostered the development of informal networks providing support for mothers outside the scheduled meeting times to deal with day to day issues. For one participant:

I kind of needed to be around people in the same situation . .. one of her friends has a learning disability and I would talk to her mother as to what experiences she was having, and that kind of thing. 


\section{An Uncertain Future}

Looking ahead is filled with uncertainity when you have a child with a learning disability. A sixth theme identified was an uncertain future. The sentiment expressed was that of concern. These mothers worried about their child's future and the implications it may have for their family. When children are young the tendency is to focus on an immediate problem and the next stage of education such as, primary / elementary school. There is always a worry about the future as a child progresses. Mothers hope that a child's problem will be addressed and resolved successfully.

These participants experienced a heightened concern for the future and became increasingly worried as their children progressed from year to year especially if their child's performance continued to be significantly affected by the learning disability. One mother stated as her child approaches post-secondary education:

The future is really looking less clear. When [they're] in school, you figure you start to learn the little things you have to deal with, but now we're going down a whole new road.

A fundamental concern described by these participants was whether their child would be able to support himself / herself and be able to function independently. A common hope expressed by these mothers was that their children would turn out to be independent, capable adults, confident in making their own choices and decisions, and able to have a good quality of life. Beyond this, they indicated wanting their children to achieve their full potential to the degree possible and establish careers in which they 
would be happy, successful, and enjoy a good standard of living. A shared sentiment described was:

All I want is for him to have contentment and to know you have, you are a reasonable adult, you can make choices and, when you make them, make another one the next day and go on from there.

They realized, however, that further education and/or training is often a prerequisite for the attainment of such goals in modern society. Schools, government, and employers emphasize the importance of post-secondary education at the university or college level in establishing a career. While some mothers were watching their children progress successfully through post-secondary education, others had many doubts whether a post-secondary education is an appropriate or realistic choice for their child.

A major area of concern for some participants was whether their child would be able to identify potential vocational or career paths suited to their interests / capabilities that would lead to reasonable employment prospects. All mothers were aware that impediments imposed by particular learning disabilities might severely restrict opportunities for their child. Increasing educational and skill requirements for many jobs in recent years as a result of the introduction of new technology and changing demands in the workplace concerned these women. Also frustrating for some mothers was the knowledge that many positions are casual, part-time, and/or contractual, and do not offer any sense of permanency. These realities added to their anxiety and concern that their child might not be able to become independent. 
All participants were aware of the pressures and stresses of the modern workplace, as well as the challenges their children would likely face in today's highly technological and competitive world. Depending on the nature of a child's disability, mothers knew that the work environment might pose challenges for their child. Since these women understood the strengths and limitations of their child, they were unsure whether their child would be ready and able to cope satisfactorily in the workplace. One mother stated:

We're worried about her future, actually what we have to do is try... to zero in on what are her strengths . . but I don't know how that translates into job possibilities. We'd like to concentrate more on whatever her strengths are in general and build that up now while she's still young so that maybe she'll be able to get employed when she gets older.

Some women expressed concern about their child's interest and willingness to embark on post-secondary education. The prospect of several more years of formal education or training may be daunting to a child who has already struggled for thirteen or more years to get through the school. For one participant:

And now then we have to face the possibility, the very real possibility that she may, you know, not be able to go to university. . . with the difficulty we're having of trying to get her to, to pass her subjects, you know, I don't know if she's really going to choose to go to college and to have to be under this type of stress.

A concern about the post-secondary education system and a child's ability to succeed in that system was another major worry for one mother. Whether her child would 
be able to qualify for institutions and/or specific programs in which the child was

interested created anxiety and feelings of uncertainty. As she described:

You wonder well, if she'll be able to get into postsecondary institutions, and what it will be like for her when she gets in, because this is another level of education, and so you got to make sure certain supports are there, but yet she's becoming independent and will she be able to [be] come more independent. I'm getting more and more scared.

One mother expressed concern over not knowing what she would do in the event that her child was turned down from a program and found this prospect to be very troubling. Acceptance to programs is based on performance measures such as high school grades and other testing. As she revealed:

She'd always wanted to be a [particular career] and I don't think I can tell her she can't be, and that [I want to] leave her to have this goal, but [I wonder] will she be able to do that, and how will she adjust if she can't reach that goal.

All women indicated they would provide whatever assistance was needed to help their child get a vocation or career and to support them in a successful transition into the adult world. They anticipated, however, that the needs of their children would likely be very different at this stage than through the school years and expressed trepidation at exactly what their role might be.

Preparing for the future in terms of parental absence due to sickness, death, or some other reason was expressed by one mother. Extra-ordinary efforts went into organizing schoolwork and progress reports so that other knowledgeable people would be able to assist with a child's educational needs. 
One participant indicated she did not want to burden a sibling with responsibility for looking after a brother or sister in the event that she could no-longer do so. It was felt that siblings were already affected to some degree and it would be unfair to burden them further. Realizing, however, that the possibility might exist she explained:

I mean if he's never. . . [to] function independently, then I have to help him, and when I'm not around to help him his [sibling] probably has to help him, and I think that's a big responsibility for a sibling.

The financial costs associated with post-secondary education or training was also a major concern for these women. Many families had spent a great deal of money over the years for support services such as tutors, counselling, occupational therapy, speech therapy, private schools, and assessment to help their child get the help they needed. Some mothers worried that such costs would not only continue through their child's postsecondary program but might in fact balloon because of the need for higher level tutors and extended contact time for their child to learn the material involved.

Many mothers felt that they would need to continue working at least until their child had finished his/her program, and/or was established in a reasonably stable position in order to cover additional expenses. The high cost of post-secondary education for a child with a learning disability was considered to be a major determinant of whether one or both parents could financially afford to retire as anticipated. Other mothers felt that if their child did not pursue a college or university program they would have to support him/her to some degree and/or help them to secure employment. A child's future needs were, therefore, a key factor in terms of retirement planning and their freedom. The 
biggest problem was that these needs could not be determined very far in advance or with any reasonable degree of certainty. These women accepted the possibility that their child could be living at home for several years. As one mother put it:

You know that she's going to be with us for a bit longer.

Women worried about the underlying cause of their child's learning disability and its likelihood to resurface in future generations. One mother expressed concern about grandchildren and would be watching carefully for any signs of learning disabilities in the hope that any problems could be dealt with sooner rather than later.

All women expressed sentiments of the public's lack of awareness about learning disabilities and the need for education.

[What] I would like to [see] happen is more public awareness.

I'd like to see it made easier, [with] more awareness and more understanding. 


\section{CHAPTER 5}

\section{DISCUSSION}

Analysis of the interview data suggests that being a mother of a child with a learning disability is a challenging and complex experience filled with pain, frustration, emotion, and stress. Literature reviewed in relation to learning disabilities and mothers / parents also illustrated similar findings. Stress occurs in parents of children with learning disabilities when their capacity to fulfil their parenting role is surpassed by demands made upon them by a child (Pearson \& Chan, 1993). Parents' ability to perform their child rearing roles effectively within the family depends on role demands, stresses, and supports from other settings (Bronfenbrenner, 1979). Many of the stresses associated with the work of mothering are "invisible" to others (Brown, Lumley, Small, \& Astbury, 1994). The special challenges of dealing with a child with learning disabilities and the excessive amount of time involved, certainly placed unusual demands upon mothers in this study which were often unrecognized. Burke and Cigno (1996) suggest that parents seem to exist in a day-to-day state of uncertainty and stress which is probably connected with their not being understood and heard.

Certain conditions do place unusual demands on mothers (Nelson, 2002).

Identification of a learning disability in a child's early developmental period is unusual (Faerstein, 1981). Mothers, therefore, search for answers as to why their child is not performing like other children. Consistent with the literature reviewed mothers looked for outside help and resources, assumed an advocacy role, and were active participants in 
their child's life, especially their education. This chapter is a discussion of the identified themes as they relate to the literature.

\section{Discussion of Themes}

Several themes were identified from the research data. The themes - searching for answers, easing the child's struggle, need for assistance and understanding, no time for self, isolating and lonely life, and an uncertain future - are the parts which, together with their interrelationships, provide a picture reflecting these mother's experiences.

Searching for answers indicated that these women sensed something was wrong in their child's pre-school years. They were unable to clearly understand and define the problem. Their concerns arose from behaviours observed in their children, or noticed in comparison with the performance of siblings, or other children of the same age. Problems such as having difficulty learning how to read, poor printing, no interest in learning the alphabet and/or colours, were some areas in which mothers expressed concerns. Blumsack et al. (1997) also found that problems were observed in the early years, the most commonly described falling within the categories of academic skill, social behaviour, and difficulty paying attention. In all cases, the early suspicions of the mothers were not confirmed as learning disabilities until later - in some cases many years later and only after persistent intervention and advocacy efforts. This finding in my study suggests that mothers are reliable and accurate observers of a child's development and these problems could be addressed more quickly if these concerns were heard. Presence, of these problems in the pre-school period, is an early indicator of potential difficulties. 
This also demonstrates the importance of listening to what mothers have to say, exploring their concerns with them, and evaluating their situations on a regular basis.

The women interviewed felt compelled - perhaps driven by the mothering instinct - to actively confirm or dispel their suspicions, and to seek answers. Their concerns, as well as, their sense of urgency to understand and address their child's problems increased when their child entered the school system. The signs of learning disabilities became increasingly more apparent upon school entry, and shortly thereafter, because the environment is more structured and performance expectations are more measured.

While mothers knew there was a problem, the greatest difficulty was getting professionals to agree that a problem existed. Glascoe (2000) emphasised the importance of having concerns about children's behaviour and development addressed by professionals. Some women interviewed felt one of the reasons for not getting acknowledgement / agreement that a problem existed was the fact that their child managed to get through their work and progress from grade to grade despite constantly struggling with the material and the environment. They also did not create any behavioral difficulties in the classroom, therefore, did not demand special attention. This suggests that children with behavioral problems are more likely to receive intervention. The need exists, therefore, to be aware of the needs of all children especially when mothers have voiced their concerns and have documented examples to illustrate their problems.

For the mothers interviewed, the process of confirming their child's problem was a two step process. The first step was having some professional such as a teacher, community health nurse, or family physician, initially agree there is a problem. The 
second step was referral to a specialist, such as, an educational psychologist for further assessment. Another major problem found in this study was that the long delay experienced in trying to get an assessment done within the school system was very frustrating for mothers. Due to the waiting time associated with assessments some women chose to have their child evaluated through private practitioners. While this may be a quick solution, not all families might be able to afford this route. This suggests examination of the existing system is necessary to see how waiting times could be improved.

I found that trying to get the problem identified was exhausting and time consuming. This was also described by Waggoner and Wilgosh (1990) and Dyson (1996). Some initial assessments even indicated that there was no problem. Instead of relieving their concerns such results tended to add to the frustration and anxiety of these mothers. Some mothers interviewed described struggling until high school before identification of a learning disability occurred. The anguish experienced by these mothers was a tremendous burden extending over many years. The eventual identification of the problem was due to these women persevering with professionals and systems until finally they had an answer confirmed their concerns.

The experiences of mothers in my study with teachers and school were both positive and negative as also reported by Waggoner and Wilgosh (1990) and Dyson (1996). For some mothers in my study, more positive experiences occurred at the junior high and high school levels. This could be due to children having developed strategies to deal with their problems, educators / administrators being more aware of learning 
disabilities, knowing the struggles that mothers / parents experienced over the years and wanting to help, and the continued involvement of these women in their child's education. Cases where educators / administrators lacked an understanding of learning disabilities and the needs of these children and their parents / families, even when a diagnosis was confirmed, contributed to the creation of negative school experiences for mothers in my study.

Depending on the nature and degree of problems, children with learning disabilities seldom present any visible signs. In the great majority of cases they are indistinguishable from other children. While this "invisibility" may shelter a child from stares or other forms of unwanted attention, it often precluded others including teachers, family, and friends from recognizing that a child had a problem, needed assistance, and required appropriate allowances. More education and public awareness of learning disabilities, therefore, is necessary. Unless one has knowledge and knows what to look for in terms of specific learning disabilities, it is hard to recognize the problems.

"Invisibility" of the disorder was also found to add stress to parents in research by Margalit and Heiman (1986). This "invisibility" and the appearance of not being ill to others, contributed to the difficulty of identifying the problem, and mothers often being blamed for a child's hyperactivity or impulse control (Faerstein, 1986). One mother related being told that the behaviour of her child was the result of her parenting.

The identification of a learning disability brought relief and was welcomed by all mothers interviewed, as also reported by Faerstein (1986). This was due to the fact that mothers in my study had struggled for a long time with the problem and were glad that 
others now recognized / agreed with what they had been saying. For some mothers it was the start of obtaining the resources their child needed to facilitate learning. This finding, however, was contrary to research by Dyson (1996) where some parents were reported to have expressed difficulty accepting and admitting the diagnosis of a learning disability.

The desire to ease the child's struggle and to help the child stemmed from mother's nurturing instinct, observations of their children's struggles, and the desire to improve their child's situation. While many fathers also shared concerns and were supportive, it was the mothers who assumed leadership and responsibility in assembling and providing the help their child needed. This desire to help their child is in fact the driving force behind their early concerns about their child's development and their search for answers.

All women interviewed attempted to provide help to address the problems they perceived with their child long before a learning disability was confirmed. They were, however, unprepared for this role. Mothers are often at a loss to know what to do and are not prepared for the problems they face when their child with a learning disability enters the school system (Gallagher, 1994). The search for a clear diagnosis of the problem is prompted in part by a desire to bring focus to the problem and to identify proven strategies for providing needed help.

Areas in which mothers found it especially difficult to provide help to their child were: (a) interpreting verbal and written information presented to their children or the way instruction had been given, (b) inability of a child to follow multiple instructions in the classroom and at home, (c) capacity to retain information for test performance, (d) 
capability to take notes in class, (e) staying on task to complete homework and other tasks within a reasonable period of time, and (f) child's lack of organizational skills.

The demands of school and especially homework were overwhelming and stressful for mothers. Women in my study, therefore, needed to be actively involved in their child's education and to provide instruction at home for their child to get through the schoolwork. This was reported in the findings of Waggoner and Wilgosh (1990) and Dyson (1996). In order to do this, however, they also needed to become informed about the materials being covered and learning expectations. These tasks made excessive demands on time and in some instances their own capabilities. Where possible, they sometimes enlisted help from fathers, siblings or even paid tutors, but ultimately took responsibility for co-ordinating these interventions and ensuring that the work was covered.

Need for assistance and understanding surfaced for these women when they recognized they could not deal with their child's problem on their own. These mothers expressed working with systems to find help for their child was fraught with numerous challenges and frustrations. Some difficulties experienced were: (a) lack of awareness of where to go for help, (b) absence of a diagnosis and "label" for the problem in some instances without which services were unavailable to help their child, (c) lack knowledge of what to do to remedy their child's situation when no diagnosis was confirmed, and (d) lack of co-ordination of support services and communication between and within disciplines. 
Mothers in my study described acting as an advocate for their child performing the role of teacher to assist with homework which involved reading and preparation to understand content of the material, employing tutors, co-ordinating and attending meetings with teachers, as well as, others working with their child. Faerstein (1986) reported that mothers often showed great ingenuity in obtaining necessary services for their child. Women interviewed reported that if they were not "visible" and actively involved in the educational process, their child would not get the services they needed. These mothers considered continuous communication an essential role. The cost of tutors and private assessment created financial concerns for families in my study, as well as, those families participating in studies by Waggoner and Wilgosh (1990) and Dyson (1996).

Professionals were necessary resources used by mothers in my study to gain information about a child's difficulties and how to remedy problems. Some mothers indicated using counselling services to help their child. Pain (1999) found communication for information was important to understand a child's learning disability and this was necessary to give parents sufficient knowledge so they could plan and feel in control of family life.

Professionals, while concentrating on specific problems, seemed to be working in isolation and lacked a team approach to share with each other their focus, the objectives / goals for a particular problem, and progress made. Mothers in my study, therefore, felt it was their responsibility to get information from outside support disciplines / professionals that were helping their child to present at school meetings when looking for resources 
that could improve a child's learning environment. This role assumed by mothers consumed numerous hours to co-ordinate / accumulate information and was deemed essential to make sure all that involved were aware of a child's problems and needs. This suggests the need for all individuals dealing with the child's learning disability to confer on a regular basis promoting a team approach. While it is understood this would require time, the co-ordination might prevent needless frustration by all involved leading to a more satisfactory working partnership and greater success.

The need to support mothers having a child with a learning disability was found in my study. Hogan, Linden and Najarian (2001) indicated support for parents may be in the form of information (informational), verbal and non-verbal communication (emotional), and providing physical assistance (instrumental). Support can come from (informal) natural support systems such as family and friends, or from (formal) support systems such as professionals and groups experiencing similar problems. Mothers interviewed experienced support that was both positive and negative from each of these support systems. The need for emotional support was very important. Support seemed to be sporadic in nature within the systems and appeared to depend on the awareness and knowledge of learning disabilities by those people mothers encountered. Mothers willing to share their needs and experiences with other mothers through support group meetings held by the Learning Disabilities Association and/or telephone conversations with this Association found this to be a valuable way of deriving informational and emotional support. Varying degrees of support was also discovered by Waggoner and Wilgosh (1990). 
All mothers in my study required some level of support and networks of support services. Families should have a choice of support that is helpful to them (Burke \& Cigno, 1996). The findings of McGill (1996) and Pearson and Chan (1993) indicated that respite for mothers were very helpful. Timing the respite when mothers perceived it necessary was suggested, additionally residential care was found to reduce parental stress. Pearson and Chan and Waggoner and Wilgosh (1990) have noted the need for social support when having a child with a learning disability. This suggests the need for development of resources, such as, camps that would provide a measure of respite for mothers and families.

Stress was a part of the lives of these women / families as also reported in other research (Dyson, 1993/1996; Fuller \& Rankin, 1994; Pearson \& Chan, 1993). Stress was attributed to the multiple roles and responsibilities that were assumed in everyday living having a child with a learning disability and time required completing homework. Dealing with various systems, continuous communication and collaboration with professionals, lack of time for self and other family members, as well as, a lack of diagnosis of the problem, added stress to the lives of these women.

Stress in any given school year was reported to be determined by whether or not a child's teachers / others working with their child was receptive and understanding of the mother's concerns, and was willing to provide support even if a learning disability had not been confirmed. Stress was also associated with uncertainty about a child's future. Some participants described experiencing high levels of stress necessitating time off from their employment. Stress in a family may also be the result of anger, oppositional and 
controlling behaviour, demanding needs and difficulty, which in turn generates stress for everyone else (Silver, 1993). One mother experienced stress from these other sources with her child. Early identification, therefore, would help to reduce the stress experienced by these women and their families.

Another theme expressed by mothers was having no time for themselves. Mothers related the additional responsibilities, the demands on time in helping a child with a learning disability, and their work resulted in no time remaining for social and leisure activities. Some mothers stated that they were too exhausted to participate in social and leisure activities even when if there was some time available. Pearson and Chan (1993) suggested in their findings that mothers lacked the emotional resources and time to develop relationships outside the home due to their working full time and caring for their family.

The women interviewed all stated that they needed to be extremely organized in their own lives in order to be available to help their child. This was also reported by Margalit and Heiman (1986). Moreover, many found it necessary to impose organization and structure on their child with a learning disability in order for them to meet their responsibilities and expectations. They spent a great deal of time with their child having a learning disability doing homework, building self-esteem and confidence, dealing with the issues related to their child's learning disability, and problems all children face. This finding was also discovered by Waggoner and Wilgosh (1990) and Dyson (1996). This huge commitment of time was also necessary for their children to achieve success especially in the school system. 
These women promoted additional opportunities for learning and confidence building for their children outside the more formal educational system through involvement in voluntary organizations. Emphasis on personal achievement and growth of children was also reported in the findings by Dyson (1996) and Margalit and Heiman (1986). Some mothers interviewed indicated spending time together as a family involved selecting activities that suited their child with a learning disability rather than pursuing something on their own. This was contrary to the findings of Dyson who found some families indicated having reduced time together.

Women interviewed indicated feeling lonely and isolated from family and friends. This loneliness originated from their perception of being alone in their struggle to get help for their child since no one seemed to understand the problem as they saw it even professionals. Mothers accepted the fact that some people, including family, were not able to understand the nature of their child's problems and the level of effort required of them. Some mothers felt that only those living the experience could truly understand it and loneliness was the result of not having someone close that they could talk to and share experiences. Lack of support from families, parents, and husbands was also reported by (Faerstein, 1986). Feelings of being alone, consequently, created a sense of separateness and distance from everybody else. This was an enormous burden for these women that did not go away.

Some mothers related that they had concerns about their own mental health from being tired and exhausted. Their involvement in helping others with similar challenges, however, promoted coping with their own situations. This suggests that support groups 
played an important supporting role for these mothers and illustrates the need to assess the mental health of mothers when working with families who have a child with a learning disability.

An uncertain future was another theme identified for these women. For all of the mothers the future was filled with uncertainty and concern. All women in my study worked diligently to make sure that their children would complete their education, gain employment, become independent, and have a good life. Whether or not this would happen was uncertain for some of the mothers interviewed. Success in education and the future was felt to be dependent upon how well these women were able to navigate systems to obtain resources. This finding was also reported by Waggoner and Wilgosh (1990). For some mothers it was too early to know whether their hopes were realizable because of the age / grade level of their child. Whether they would be successful in arranging and mobilizing appropriate resources, as well as, intervention strategies was also an unknown. Some mothers expressed concerns over whether or not their child would indeed want to pursue any post-secondary education due to the level of effort required. This suggests that mothers continually need to have access to support from professionals, groups, and others to facilitate any concerns / questions.

The potential for learning disabilities to surface or even be accentuated in future generations was also expressed. There is evidence to support that some learning disabilities have a genetic cause (Bender, 2001). Open discussion about specific disabilities within families and what to look for, might help successive generations to identify likely problems early and to get appropriate interventions in place. Such early 
interventions may improve the outcomes for the child and reduce the stress and burden on mothers.

Financial planning and the high cost of post-secondary education were indicated as concerns by some women interviewed. Concerns over the future needs of their child and the associated financial costs also raised doubts about when one or both parents would be financially able to retire.

Mothers related that siblings were affected by the presence of a child with a learning disability consistent with the findings of Burke and Montgomery (2001) and Glendinning (1986). The women I interviewed described that some siblings, depending on their ages, helped out the mother in meeting the needs of the child with the learning disability. Waggoner and Wilgosh (1990) also reported this finding. One mother related being concerned that the siblings of the child with a learning disability might have to assume responsibility for the care of their brother / sister in the adult years. This created pressure for this mother to secure the help her child needed to prevent this additional role for siblings.

The findings of Evans, Jones, and Mansell (2001) found that support groups were positive in helping siblings cope and understand needs and behaviours. This suggests an opportunity for the introduction and development of such support groups in the local community.

There were no problems expressed regarding substance use or other delinquent behaviours with a child having a learning disability among my participants. Some women, however, expressed concerns about low levels of self-esteem and confidence in 
their child with a learning disability and were particularly watchful for potential situations that might create problems. One mother expressed concern over her child's high anxiety level and the potential effect this might have on his future if not satisfactorily resolved. The findings of Beitchman et al. (2001), McBride and Siegel (1997), and Silver (1993) found that untreated or poorly treated learning disabilities put children at risk for development of behaviour problems and psychiatric disorders.

\section{Summary}

In summary this study contributed more detail and a greater understanding of how a woman with a child who has a learning disability is able to mother that child. It provides insight into some of the particular concerns she has about her child's ability to develop socially and pursue an education. It also helps to demonstrate the frustration that mothers have when their concerns are not addressed. 


\section{CHAPTER 6}

\section{NURSING IMPLICATIONS AND CONCLUSION}

Findings from this study have illustrated that mothers are greatly affected when they have a child with a learning disability. Women experienced stress as a result of trying to find an answer to their child's problems. These mothers were exhausted due to the multiple roles assumed in order to deal with the needs of their children, as well as, caring for other members of their family and their added responsibilities. Mothers have intuition and insight into their child's problems that is often unrecognized by others. There is an increased need to acknowledge the special role, issues, and concerns of women who have a child with a learning disability. This chapter contains implications for nursing practice, education, and research.

\section{Nursing Implications}

Phenomenology using van Manen's (1997) approach provides an understanding of the nature of the meaning of the everyday experience as described by mothers who have a child with a learning disability. Understanding the meaning of that experience and seeking knowledge is consistent with the holistic philosophy of nursing in which we try to address all aspects of an individual's problem. This understanding has implications for nursing practice, education, and research. 


\section{Nursing Practice}

There is much that the nurse who comes in contact with mothers, such as the ones I interviewed in this study, can do to help women and their families who find themselves in a similar circumstance. The first is in identifying children who may be affected by a learning disability and working with other health professionals to see that the child is assessed and the problem identified. While most areas of nursing practice afford opportunities to interact with mothers and children, the area of community health nursing practice provides unique opportunities to meet with people in their homes and communities. Interaction through child immunization programs delivered through community health nursing might be one of the first places where women voice their concerns about a child's development. Additionally many concerns of mothers are addressed informally to nurses while visiting another family member. Being listened to was a major concern for mothers in this study. Several nursing implications are evident in a variety of nursing roles.

By using their clinical skills nurses can act as case finders though well child clinics and pre-school health checks when they assess children's development. Appropriate referrals could be made to link mothers needing further assessment for their child with appropriate services or community resources. The nurse could highlight potential concerns and follow a child as he/she progresses through pre-school and school years in community health nursing practice where this is possible. Nurses could facilitate mothers getting follow-up for their concerns. This early assessment and identification is important to alleviate some of the frustration and stress these women experience. The 
nurse can also act as a support for the mother as she gets the child's problem diagnosed. When working with mothers of children with learning disabilities, it is important to assess the woman's mental health and suggest appropriate interventions to alleviate stress. In the roles of educator and consultant nurses can act as resource professionals to mothers, other family members, and groups by providing information regarding normal growth and development of children. The nurse could also educate these individuals and groups about what to look for if a learning disability is suspected. Nurses can conduct / co-ordinate formal presentations to individuals and groups interested in learning more about learning disabilities. Teachers and the general public can become more aware of the health implications of learning disabilities through public education efforts of nurses.

Nurses can also function as team members or collaborators with other professionals, especially teachers and school principals, and foster interdisciplinary linkages for the purpose of sharing information, setting goals or objectives to help address problems and meet individual needs of children with learning disabilities and their families. This would lead to improved care when assisting families so affected.

Another important role for nurses is advocacy. The provincial government's policy framework, The Strategic Social Plan (SSP) for Newfoundland and Labrador, 1998, encompasses the concept of investing in people through the early identification and intervention planning for children. In particular the SSP states as a mandate: "Strengthening programs directed at supporting children and their families prevents problems before they arise, and before they become difficult, painful, and expensive to solve" (p. 11). Making sure that children with disabilities and those at risk for school 
problems can partake in early intervention and stimulation programs results in considerable savings to society in terms of curtailing school drop-out rates, criminality, teen pregnancy, and unemployment (Glascoe, 2000). Nurses can help advocate for approaches to health care that invests in the health and well being of key population groups such as children and families with children and youth (Toward a Healthy Future, 1999).

Healthy public policy includes health promotion, disease prevention, and providing health care services that include social and educational concerns (Anderson \& McFarlane, 2000). There is a need, therefore, for public policy that recognizes mothers are primary caregivers of children with learning disabilities and that they need support. The health care system must be prepared to assume a much larger role for people with learning disabilities. A review of current priorities and practices surrounding public policy and learning disabilities is suggested.

\section{Nursing Education}

Given how widespread the problem of learning disabilities is there are a number of implications for nursing education. It is important to educate nurses about learning disabilities and the effect these conditions have on affected individuals and their families. Nurses need to have an understanding of these conditions and different signs and symptoms of learning disabilities, the needs of people who are affected, and knowledge of various strategies to promote learning among people affected. 
Nurses who work in community health and school health programs need additional preparation on how to identify and work with children and adults who have learning disabilities. For example in school health programs, nurses need to know how to adapt health promotion literature and provide instruction to children with learning disabilities. Nurses, therefore, need to be better equipped to understand the unique issues and problems involved with learning disabilities. These approaches may help reduce the frustration people with learning disabilities and their families have when encountering the health care system.

\section{Nursing Research}

Nurses could conduct further research to understand and gain awareness of the issues, concerns, and needs of individuals and families having a child with a learning disability. Findings can then be shared with colleagues and interested community members and may also suggest the need to review existing policy. There is a great need for evidence on which to base practice for this vulnerable group and their families.

Nursing research helps create knowledge for description and explanation of phenomena. Nursing research is a powerful way to provide program planners and policy makers with the background information needed to frame new policy (Tan, Hayes, \& Hollander, 2000). From my literature review there seems to be very little nursing research that examines the effects that children with learning disabilities have on their mothers and families. There are, therefore, many areas for exploration and implications for nurse researchers using both quantitative and qualitative methodologies. 
Several quantitative studies could be conducted using a descriptive correlational design. One could investigate parental stress, coping, and adaptation of mothers as their children with learning disabilities make the transition from junior high school, to high school, to post-secondary education. Another could examine the relationship between stress, coping resources, and satisfaction with family functioning in a group of parents with children having learning disabilities. Another could identify how effective social support is in moderating the negative effects of stress on family functioning and family hardiness for a group of parents who have children with learning disabilities. Other studies could describe the differences in parental stress between mothers of children with and without learning disabilities in elementary, junior high, high school, and postsecondary education.

Several other qualitative studies using phenomenology could be conducted. These might provide an understanding of the experiences of the following: fathers of children with learning disabilities, teachers having children with learning disabilities in their classes, adults with learning disabilities, as well as, siblings of brothers and sisters who have a learning disability. Parents of children with learning disabilities and the children themselves could be studied for the purpose of generating grounded theory on how they cope with the disability.

Longitudinal studies could be undertaken to track the experiences of a sample of mothers examining, for example, parental stress and family functioning as their children progress from one level of education to another. Longitudinal studies would reveal what happens to these women over time, and identify patterns of change and reasons for 
change, while adding to the body of knowledge regarding mothering and learning disabilities. The use of quantitative methodology would also serve to generalize results. Qualitative methodologies would explore the lived experiences of individuals and might aid in the development of mid-range theories, as well as add to knowledge of learning disabilities and especially families who deal with these disabilities.

\section{Conclusion}

The fundamental question asked in this study is what is it like to be a mother of a child with a learning disability. To achieve an answer the research methodology chosen was phenomenology using the approach of van Manen (1997) for analysis of the interview data. Ten women were interviewed for this study. A literature review was conducted to provide an understanding of learning disabilities and what research was conducted on mothers' experiences. From an analysis of the interview data, six themes were identified. They were searching for answers, easing the child's struggle, need for assistance and understanding, no time for self, isolating and lonely life, and an uncertain future. Discussion of the findings was presented followed by implications for nursing practice, nursing education, and nursing research. Being a mother of a child with a learning disability is very challenging, stressful and frustrating experience consuming a great deal of their time. 


\section{REFERENCES}

Anderson, E. T., \& McFarlane, J. (2000). Community as partner: Theory and practice in nursing. $\left(3^{\text {rd }}\right.$ ed.). Philadelphia, PA: Lippincott.

Beitchman, J. H., Wilson, B., Douglas, L., Young, A., \& Adlaf, E. (2001). Substance abuse disorders in young adults with and without LD: Predictive and concurrent relationships. Journal of Learning Disabilities, 34, 317-332.

Bender, W. N. (2001). Learning Disabilities Characteristics, Identification, and Teaching Strategies ( $4^{\text {th }}$ ed.). Needham Heights, MA: Allyn and Bacon.

Betz, C. L. (1998). Adolescent transitions: A nursing concern. Pediatric Nursing, 24(1), 23-28.

Blumsack, J., Lewandowski, L., \& Waterman, B. (1997). Neurodevelopmental precursors to learning disabilities: A preliminary report from a parent survey. Journal of Learning Disabilities, 30, 228-237.

Bronfenbrenner, U. (1979). The ecology of human development: Experiments by nature and design.(pp. 3-15). Cambridge, MA: Harvard University Press.

Brown, S., Lumley, J., Small, R., \& Astbury, J. (1994). Missing Voices: The experience of motherhood (pp.161-172). Melbourne, Australia: Oxford University Press.

Burke, P., \& Montgomery, S. (2000). Siblings of children with disabilities: A pilot study. Journal of Learning Disabilities, 4, 227-236.

Burke, P., \& Cigno, K. (1996). Support for families. Helping children with learning disabilities. Avebury, England: Ashgate.

Comfort, R. L. (1992). Living with the unconventional child. Journal of Pediatric Health Care, 6, 114-120. 
Dyson, L. L. (1993). Response to the presence of a child with disabilities: Parental stress and family functioning over time. American Journal on Mental Retardation, 98, 207-218.

Dyson, L. L. (1996). The experiences of families of children with learning disabilities: Parental stress, family functioning, and sibling self-concept. Journal of Learning Disabilities, 29, 280-286.

Evans, J., Jones, J., \& Mansell, I. (2001). Supporting siblings: Evaluation of support groups for brothers and sisters of children with learning disabilities and challenging. Journal of Learning Disabilities, 5, 69-78.

Faerstein, L. M. (1981). Stress and coping in families of learning disabled children: A literature review. Journal of Learning Disabilities, 14, 420-423.

Faerstein, L. M. (1986). Coping and defense mechanisms of mothers of learning disabled children. Journal of Learning Disabilities, 19, 8-11.

Federal, Provincial and Territorial Advisory Committee on Population Health. (1999). Toward a Healthy Future, Second Report on the Health of Canadians. Prepared for the Meeting of Ministers of Health, Charlottetown, P.E.I.

Foruqurean, J. M., Meisgeier, C., Swank, P. R., \& Williams, R. E. (1991). Correlates of postsecondary employment outcomes for young adults with learning disabilities. Journal of Learning Disabilities, 24, 401-405.

Fuller, G. B., \& Rankin, R. E. (1994). Differences in levels of parental stress among mothers of learning disabled, emotionally impaired, and regular school children. Perceptual and Motor Skills, 78, 583-592.

Gallagher, L. N. S. (1994). The impact of learning disabilities on families. Journal of Child Neurology, 10 (Supp1. 1). S112-S113.

Glascoe, F. P. (2000). Evidence-based approach to developmental and behavioural surveillance using parents' concerns. Child: Care, Health and Development The Multidisciplinary Journal, 26, 137-149. 
Glendinning, C. (1986). A single door: Social work with the families of disabled children. London: Allen and Unwin.

Government of Canada. (2002). Knowledge Matters: Skills and learning for Canadians. Retrieved January 18, 2003 from http://www.hrdc-drhc.gc.ca/sp-ps/slca/doc/section1_e.shtml

Government of Newfoundland and Labrador. (1998). People, partners and prosperity: A strategic social plan for Newfoundland and Labrador Chapter 2. Retrieved March 3, 2002 from http://www.gov.nf.ca/ssp/

Greenspan, M. (1998). "Exceptional" mothering in a "normal" world. In C. G. Coll, J. L. Surrey, \& R. Weingarten (Eds.). Mothering against the odds diverse voices of contemporary mothers (pp. 37-60). New York, NY: The Guildford Press.

Grolnick, W. S. \& Ryan, R. M. (1990). Self-perceptions, motivation, and adjustment in children with learning disabilities: A multiple group comparison study. Journal of Learning Disabilities, 23, 177-184.

Hogan, B. E., Linden, W., \& Najarian, B. (2002). Social support interventions: Do they work? Clinical Psychology Review, 22, 381- 440.

Kavale, K. A., \& Forness S. R. (2000). What definitions of learning disability say and don't say: A critical analysis. Journal of Learning Disabilities, 33, 239-256.

Margalit, M., \& Heiman, T. (1986). Family climate and anxiety in families with learning disabled boys. Journal of the American Academy of Child Psychiatry, 25, 841846.

McBride, H. E. A., \& Siegel, L. S. (1997). Learning disabilities and adolescent suicide. Journal of Learning Disabilities, 30, 652-659.

McGill, P. (1996). Summer holiday respite for the families of children and young people with learning disabilities. Child: Care, Health and Development The Multidisciplinary Journal, 22, 203-212. 
Memorial University of Newfoundland. (2001). Policy statement on integrity in scholarly research. Retrieved July 3, 2002 from http://www.mun.ca/research/resadmin/integrity\%20.html

Nelson, A. M. (2002). A metasynthesis: Mothering other-than-normal children. Qualitative Health Research, 12, 515-530.

Pain, H. (1999). Coping with a child with disabilities from the parents' perspective: The function of information. Child: Care, Health and Development The Multidisciplinary Journal, 25, 299-312.

Pearson, V., \& Chan, T.W.L. (1993). The relationship between parenting stress and social support in mothers of children with learning disabilities: A Chinese experience. Social Science and Medicine, 37, 267-274.

Rogers, H., \& Saklofske, D. H. (1985). Self-concepts, locus of control and performance expectations of learning disabled children. Journal of Learning Disabilities, 18 , 273-278.

Sandelowski, M. (1986). The problem of rigor in qualitative research. Advances in Nursing Science, 8(3), 27-37.

Sawin, K. J., Cox, A. W., Metzger, S. G., Horsley J. W., Harrigan, M. P., Deaton, A., et al. (1999). Transition planning for youth with chronic conditions: An interdisciplinary process. National Academies of Practice Forum, 1, 183-196.

Selekman, J. (2002). Learning Disabilities: A diagnosis ignored by nurses. Pediatric Nursing, 28, 630-632.

Silver, L. B. (1989). Psychological and family problems associated with learning disabilities: Assessment and intervention. Journal of the American Academy of Child and Adolescent Psychiatry, 28, 319-325.

Silver, L. B. (1993). The secondary emotional, social, and family problems found with children and adolescents with learning disabilities. Child and Adolescent Psychiatric Clinics of North America, 2, 295-308. 
Silver, L. B. (1996). The misunderstood child. In B. J. Cratty, B. J., \& R. L. Goldman (Eds.). Learning Disabilities Contemporary Viewpoints (pp. 1-26). Amsterdam, The Netherlands: Harwood.

Sitlington, P. (1996). Transition to Living: The neglected component of transition programming for individuals with learning disabilities. Journal of Learning Disabilities, 29, 31-39.

Smith, C. R. (1998). Learning disabilities: The interaction of the learner, task and setting, $\left(4^{\text {th }}\right.$ ed.). Needham Heights, MA: Allyn \& Bacon.

Streubert, H., \& Carpenter, D. R. (1999). Qualitative research in nursing: Advancing the humanistic imperative, $\left(2^{\text {nd }}\right.$ ed.). Philadelphia, PA: Lippincott.

Tan, E. L. C., Hayes, V. E., \& Hollander, M. J. (2000) Conducting policy research: Children with special needs. Canadian Nurse, 96(1), 27-30.

The Learning Disabilities Association of Canada. (2001). Statistics on learning disabilities (October, 2001). Retrieved June 23, 2003 from http://www.ldactaac.ca/english/indepth/bkground/stats01.htm

The Learning Disabilities Association of Canada. (2002). New current definition of learning disabilities. Retrieved March 3, 2002 from http://www.ldactaac.ca/english/defined/definew.htm

The Learning Disabilities Association of Canada. (2002). The adult with learning disabilities. Retrieved March 3, 2002 from http://www.ldactaac.ca/english/indepth/adults/adultld.htm

Tri-Council Policy Statement. (1998). Ethical conduct for research involving humans. Ottawa, ON: Author.

van Manen, M. (1997). Researching the lived experience: Human science for an action sensitive pedagogy $\left(2^{\text {nd }} \mathrm{ed}.\right)$. London, ON: Althouse. 
Waggoner, K., \& Wilgosh, L. (1990). Concerns of families of children with learning disabilities. Journal of Learning Disabilities, 23, 97-113.

Washington Summit on Learning Disabilities. (1994). Notes on the summary report. Retrieved June 23, 2003, from http://www.ldhope.com/articles/wash.html

Yonge, O., \& Stewin, L. (1988). Reliability and validity: Misnomers for qualitative research. The Canadian Journal of Nursing Research, 20, 61-67. 
APPENDIX A

\section{LETTER TO LEARNING DISABILITIES ASSOCIATION}


September 16, 2002

Ms. Patsy Whitten

Executive Director

Learning Disabilities Association of Newfoundland and Labrador

Woodgate Plaza, 58 Kenmount Road

St. John's, NF

A1B 1W2

Dear Ms. Whitten:

I have received notification from the Chairs of the Human Investigation Committee of Memorial University that my research study entitled 'Parents' Experiences of a Child with Learning Disabilities: A Phenomenological Study" has been granted full approval.

I am interested in recruiting parents with a child and/or children with an identified learning disability at the primary, secondary, high school and/or post-secondary level. The purpose of the study is to understand the impacts and consequences of learning disabilities on children and their families.

I am asking for your assistance in advising parents of this study and soliciting their interest in participating. I would need to obtain from you a list of individuals expressing such interest with telephone numbers for contact by me, the researcher. Participation would involve two audiotaped interviews lasting up to two hours each. These interviews will be transcribed verbatim and analyzed for themes. The second interview will be used to clarify responses from the first interview, examine any other areas arising from the data, and to verify and confirm findings. All information will be kept strictly confidential.

I look forward to hearing from you as soon as possible in response to this request, and would appreciate any support you are able to provide. If you have any questions regarding any components of this study, I can be reached by phone at mail

Sincerely,

Judith G. Moody, B.N., R.N. 
APPENDIX B

LETTER OF CONSENT TO PARTICIPATE IN NURSING RESEARCH 


\section{Signature Page}

Study title: Parents' Experiences of a Child with Learning Disabilities

Name of principal investigator: Judith G. Moody

To be filled out and signed by the participant:

$+$

I have read the consent [and information sheet].

I have had the opportunity to ask questions/to discuss this study.

I have received satisfactory answers to all of my questions.

I have received enough information about the study.

I understand that I am free to withdraw from the study
Please check as appropriate

Yes \{\}$\quad$ No \{\}

Yes \{\}$\quad$ No \{\}

Yes \{\}$\quad$ No \{\}

Yes \{\}$\quad$ No \{\}

Yes \{\}$\quad$ No \{\}

- at any time

- without having to give a reason

- without affecting my child's future care

I understand that it is my choice to be in the study and that I may not benefit. Yes \{\} No \{\}

I agree to take part in this study.

Yes \{\} No \{\}

Signature of participant

Signature of witness
Date

Date

To be signed by the investigator:

I have explained this study to the best of my ability. I invited questions and gave answers. I believe that the participant fully understands what is involved in being in the study, any potential risks of the study and that he or she has freely chosen to be in the study.

Signature of investigator

Date

Telephone number:

Initials: 
APPENDIX C

LETTER OF APPROVAL FROM HUMAN INVESTIGATION COMMITTEE 


\section{Memorial}

University of Newfoundland

Office of Research and Graduate Studies (Medicine)

Faculty of Medicine

The Health Sciences Centre

August 16, 2002

TO:

Ms. J. Moody

FROM: $\quad$ Dr. F. Moody-Corbett, Assistant Dean

Research \& Graduate Studies (Medicine)

SUBJECT: Application to the Human Investigation Committee - \#02.148

The Human Investigation Committee of the Faculty of Medicine has reviewed your proposal for the study entitled "Parents' Experiences of a Child with Learning Disabilities: A Phenomenological Study".

Full approval has been granted for one year, from point of view of ethics as defined in the terms of reference of this Faculty Committee.

For a hospital-based study, it is your responsibility to seek necessary approval from the Health Care Corporation of St. John's.

Notwithstanding the approval of the HIC, the primary responsibility for the ethical conduct of the investigation remains with you.

F. Moody-Corbett, PhD

Assistant Dean

$\mathrm{FMC} / \mathrm{mc}$

cc: $\quad$ Dr. C. Loomis, Vice-President, Research, MUN

Dr. R. Williams, Vice-President, Medical Services, HCC 




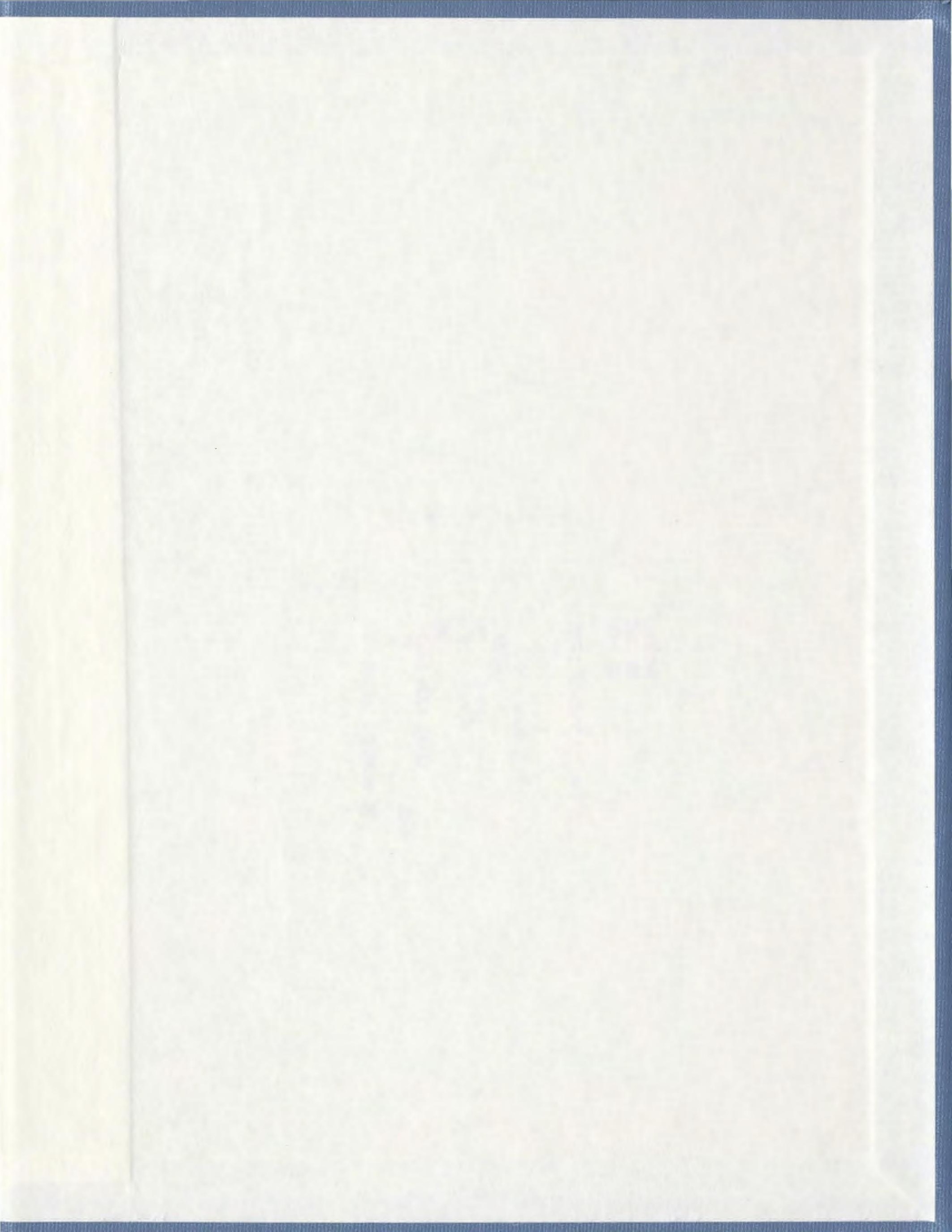


